\title{
Metaorganizadores, redes externas y conocimiento en los sectores manufactureros españoles: el papel de las instituciones locales en el distrito industrial del Vinalopó
}

\section{Meta-organizers, external networks and knowledge in the Spanish manufacturing sectors: the role of local institutions in the Vinalopó industrial district}

\author{
José Antonio Belso-Martínez \\ MARÍA JosÉ LóPEZ-SÁNCHEZ*
}

\begin{abstract}
We analyze the relevance of public and private institutions on the viability of the manufacturing industrial districts. Taking into account the growing importance of the contributions provided by Networks and Social Capital theories, we confirm the role developed by these meta-organizers of the local system as: catalysts and disseminators of knowledge obtained outside the district, coadjutors in the exploitation of new business opportunities and issuers of the local knowledge and know-how towards external environment. These results have been obtained through an empirical analysis of the Vinalopó district.
\end{abstract}

Keywords: industrial districts, SME's, local institutions, networks, Spain, globalization.

\section{Resumen}

Se analiza la importancia de las instituciones públicas y privadas en las opciones de viabilidad de los distritos industriales manufactureros. Apoyados en el creciente peso de las aportaciones de las teorías de las redes y el capital social, confirmamos el creciente papel de estos metaorganizadores del sistema local como catalizadores y diseminadores de conocimientos procedentes del entorno exterior, coadjutores en la explotación de las oportunidades de negocio o emisores de los conocimientos y saber hacer del distrito industrial hacia el exterior. Para alcanzar este objetivo realizamos un análisis empírico del denominado distrito industrial del Vinalopó.

Palabras clave: distritos industriales, Pymes, instituciones locales, redes, España, globalización.

\footnotetext{
*Universidad Miguel Hernández, España. Correos-e: jbelso@umh.es, maria.lopez@umh.es.
} 


\section{Introducción}

La globalización económica ha proporcionado un amplio número de oportunidades al conjunto de las economías desarrolladas. Sin embargo, no es menos cierto que determinadas esferas de estas economías están siendo seriamente amenazadas y, por ende, empujadas a una profunda reestructuración. Los distritos industriales se encuentran inmersos en ese grupo de realidades sujetas al cambio en pos de alcanzar una viabilidad a medio y largo plazos. ${ }^{1}$ Resultan muy conocidos los numerosos estudios sobre las transformaciones de los denominados distritos del Made in Italy (Parolini y Visconti, 2003; Basile et al., 2003; Crestanello y Dalla, 2003). También es amplia la literatura para el caso español, donde un número nada despreciable de distritos industriales vienen encontrando hipotecada su capacidad de competir en sectores económicos dominados por los nuevos países industrializados o en vías de industrialización (por ejemplo, Pla y Puig, 2009).

La Comunidad Valenciana es todavía una de las regiones españolas con mayor dinamismo exportador en el conjunto de la economía espańola. Durante los años noventa, industrias manufactureras como el calzado, juguete, textil, mueble, turrón, cerámica o mármol se consolidaron en el ámbito internacional en gran parte por la eficiencia derivada de relaciones verticales y horizontales entre pequeñas y medianas empresas (Pymes) aglomeradas en áreas geográficas concretas. Son múltiples los trabajos que han identificado estas concentraciones empresariales como distritos industriales. Sin ánimo de ser exhaustivo, podemos mencionar los estudios realizados por Ybarra (1991), Soler (2001), Hernández y Soler (2003), Giner y Santa María (2002) o Boix y Galletto (2006).

En línea con lo acontecido en otros países o regiones, los distritos valencianos también experimentan cambios que afectan a lo más profundo de sus raíces. Por ejemplo, la tradicional externalización local de actividades productivas, hoy en día se está trasladando a países con abundancia de mano de obra barata. En su análisis de las operaciones de tráfico de perfeccionamiento, Belso (2008) establece el creciente papel de los países del norte de África o de los nuevos miembros de la Unión Europea en el desarrollo de actividades intensivas en mano de obra y bajo valor añadido para el sector del calzado. Desde una perspectiva agregada, este proceso supone un vaciamiento del volumen de actividades y empleo generado en el distrito. Aunque, paralelamente, se pueda hablar de un cierto reposicionamiento al alza del mismo en la cadena de valor del sector. Algo similar

\footnotetext{
${ }^{1}$ Las diferencias entre distritos industriales y clusters han sido ampliamente mencionadas en la literatura económica. Sin embargo, en el presente trabajo consideramos intercambiables ambos conceptos.
} 
apuntan Ybarra y Santa María (2006) para el caso del juguete, donde las empresas de este sector han optado por la deslocalización, la defensa de nichos de mercado o el apuntalamiento de la actividad principal mediante negocios paralelos, como estrategias de viabilidad frente a la competencia de productos procedentes del lejano oriente.

La metamorfosis observada en los distritos manufactureros de los países desarrollados, se presenta ligada a formas colaborativas establecidas en los ámbitos económico, político y social, e integradas por múltiples actores entre los que se conforma una actitud proclive a la innovación y a la puesta en marcha de nuevas estrategias. Las instituciones públicas y privadas son algunos de esos agentes involucrados vivamente en esta dinámica de cambio, mediante el apoyo y fomento de facetas como la expansión internacional de las empresas, los servicios avanzados, las actividades de $\mathrm{I}+\mathrm{D}+\mathrm{i}$, la formación especializada y la colaboración interempresarial.

Si bien la literatura académica reconoce la relevancia de las instituciones en el distrito industrial, también pone de manifiesto la necesidad de profundizar en el análisis de las redes socioinstitucionales o prestar mayor atención a su papel en el desarrollo de un territorio (Caravaca et al., 2005). En esta línea, nuestro trabajo se propone analizar en qué medida las relaciones socioinstitucionales contribuyen a generar valor y a apuntalar la competitividad de las empresas localizadas en los distritos industriales manufactureros mediante la adquisición, elaboración y diseminación de conocimientos externos al distrito industrial. Para alcanzar este objetivo, profundizaremos en el análisis empírico de la red socioinstitucional del distrito zapatero del Vinalopó, y en los casos de dos instituciones locales clave: la Federación de Industrias del Calzado (FICE) y el Instituto Tecnológico del Calzado y Conexas (Inescop). Los resultados obtenidos reflejan que: a) existe una elevada interconexión entre los actores socioinstitucionales del distrito que contribuye a la creación de una atmósfera de confianza y la transferencia de conocimiento, y $b$ ) la integración en redes de ámbitos que transcienden al meramente local, convierte a las instituciones en receptoras/emisoras de flujos de información procedentes del exterior que serán diseminados posteriormente en el distrito. Esta evidencia respalda su papel como facilitadoras de oportunidades de negocio y coadjutoras en la explotación de las mismas.

Nuestro trabajo se estructura en cinco grandes apartados. Tras esta breve introducción, reflexionamos acerca del papel de las redes socioinstitucionales y las transformaciones del distrito industrial en la era de la globalización. A lo largo de la segunda sección presentamos la metodología empleada. En el tercer apartado valoramos los resultados obtenidos en nuestra evidencia empírica. Finalmente exponemos las principales conclusiones, implicaciones y limitaciones de nuestra investigación. 


\section{Los distritos industriales y las redes socioinstitucionales en la era de la globalización}

\subsection{Los distritos industriales: situación actual y perspectivas}

A lo largo de las últimas décadas, fenómenos de organización industrial como las aglomeraciones de empresas, los distritos industriales o los clusters de empresas han preocupado sistemáticamente tanto a los responsables de la política económica como a la investigación en materia económica y empresarial. El interés reciente en estas formas de organización industrial arranca de la actualización llevada a cabo inicialmente por Becattini (1989, 1992) y desarrollada después por autores como Sforzi (1992), Triglia (1993) o Brusco (1992), entre otros.

Inicialmente Marshall (1920), sobre la base de la industria británica, describe los distritos industriales como concentraciones espaciales donde empresas muy especializadas compiten y cooperan simultáneamente, además de que existe una densa red de relaciones socioeconómicas. Es en ese entorno geográficamente próximo donde surgen un conjunto de economías externas o efectos desbordamiento que están en el origen mismo de la capacidad de competir de las empresas. Entre estas economías destacan: la rápida propagación de nuevas ideas, una cultura semejante, similares prácticas productivas, costos de transacción reducidos o la elevada accesibilidad a servicios y recursos complementarios.

Las aportaciones marshallianas, como hemos apuntado, han resultado la base de posteriores desarrollos teóricos y empíricos sobre los distritos industriales (Corò y Rullani, 1998; Mistri, 1999; Paniccia, 1999; Belussi y Gottardi, 2000; Becattini et al., 2001; Camagni et al., 2002; entre otros). Otros autores como Cooke (1999), Cooke et al. (2000), Cook y Huggins (2002), Biggiero (2002), Keeble y Wilkinson (2000) o Guerrieri et al. (2001) han ampliado esta noción de distrito industrial desarrollando una profunda investigación sobre los denominados clusters industriales que interpretan los fenómenos de aglomeraciones de empresas como loci de desbordamiento (spillover).

Este particular modelo de organización industrial está enraizado en la base del dinamismo innovador, la trayectoria notable y el peso internacional relevante de ciertos sectores económicos y países. Así, investigaciones empíricas como las llevadas a cabo por Karlsson y Klaesson (2000), Becchetti y Rossi (2000), Paniccia (1998, 1999), IPI (2002), DTI (2001), Molina y Martínez (2003) o Belso (2006) demuestran que las empresas localizadas en los distritos industriales alcanzan mejores resultados en comparación con las que se ubican fuera de los mismos. A pesar de estos resultados, otros trabajos señalan las debilidades de este modelo 
en un contexto socioeconómico cada vez más globalizado (Pla y Puig, 2009). Entre otras podemos citar: el tradicional perfil cerrado y redundante de las redes locales o un tamaño empresarial generalmente reducido para competir en el ámbito internacional. Consecuencia de estas limitaciones, la realización de actividades de alto valor ańadido o la propia internacionalización de actividades comerciales y/o productivas, frecuentemente se transforman en una auténtica hazaña (Garofoli y Mazzoni, 1994; Gottardi, 1996).

A pesar de estas debilidades, entre los investigadores no existe un consenso sobre la decadencia o la destrucción de este modelo de organización industrial (Capo et al., 2007). Es más, algunos autores como Vaccà (1994) o Rullani (1998) aportan argumentos a favor de la viabilidad de los distritos industriales a medio y largo plazos, por ejemplo: a) la creciente demanda de productos no homogéneos, cada vez más diferenciados, y b) la vinculación de la ventaja competitiva de la empresa al entorno local, donde los agentes económicos interactúan y transfieren conocimientos. Por tanto, la economía global exige mayor especialización geográfica $\mathrm{y}$, como consecuencia, el desarrollo de sistemas locales que generen capacidades y recursos específicos difícilmente transferibles. Desde esta perspectiva, la adaptación de los distritos industriales a un choque exógeno, como la globalización, representa un paso más en su trayectoria evolutiva (Enright, 2001; Parrilli, 2004; Spaventa y Monni, 2005, 2007; Zucchella, 2006). Tras fases previas como el despegue o la madurez, la inserción gradual en los mercados internacionales supone un imperativo para un conjunto de empresas locales necesitadas de aprovechar sus capacidades mediante escalas productivas más amplias.

Sin embargo, la reciente erosión que tuvieron por las ventajas adquiridas a partir de factores estrictamente locales, ha empujado a las empresas a buscar innovaciones e inputs de alto valor añadido más allá de las fronteras del distrito. Ahora, el sistema local no se limita a ser únicamente un mero importador de inputs o un exportador de productos terminados. El distrito se convierte también en receptor y emisor de conocimientos capaces de generar ventajas alternativas (Corò y Grandinetti, 1999). Gracias a esta dinámica ligada a la innovación, algunos distritos industriales evitan un declive caracterizado por un bloqueo tecnológico, institucional, social o cultural. Así, las aglomeraciones más dinámicas optan por acometer hondas renovaciones sobre la base de densas redes locales cada vez más abiertas a recibir y emitir flujos de información desde y hacia el exterior. 


\subsection{Las redes socioinstitucionales en el distrito industrial}

Estimulados por su extraordinaria capacidad de competir y adaptarse a un entorno cambiante, los investigadores también se han preocupado por estudiar diversas facetas de la actuación pública desarrollada en los distritos industriales (Pyke y Segenberger, 1992, Garofoli, 1992; Landabaso y Rosenfeld, 2009; Boschma, 2009). En general, como apuntan Tomás et al. (2000), la misión fundamental de dicha política ha radicado en el fortalecimiento y expansión de las redes (sobre todo de tipo local) y la potenciación de una oferta de servicios especializados a las empresas. Así, el sector público asume un cierto rol de liderazgo que debiera ser capaz de aunar los intereses de todos los agentes económicos y sociales del distrito, empujándolos hacia un objetivo estratégico de largo plazo. Para ello, independientemente del instrumental o el perfil de los programas, también se ha hecho imprescindible la implicación de un conjunto de empresas líderes cuya línea de actuación tienda a ser imitada por un número suficientemente amplio de seguidoras, generando de este modo un efecto difusión (Tomás et al., 1997, 2000).

La implementación de actuaciones de desarrollo local y regional en España se ha visto muy favorecida por el intenso proceso de descentralización desde la administración central del Estado hacia las comunidades autónomas y las corporaciones locales. Son estas últimas las que, debido a su proximidad y mayor sensibilización, han tomado la iniciativa a la hora de armar una política de impulso económico y dinamización en el ámbito local (Vázquez, 1993). Más allá de las grandes inversiones en infraestructuras, en la Comunidad Valenciana muchas de las políticas se han instrumentado mediante la creación o el apoyo a una serie de instituciones públicas y privadas. Mediante estas organizaciones, los policy makers han puesto en marcha diversas acciones encaminadas a mejorar la cualificación de la mano de obra, difundir la innovación en materia tecnológica o de gestión, desarrollar actividades de $\mathrm{I}+\mathrm{D}$, promover el producto, mejorar el clima empresarial, etc. En general, la configuración de redes socioinstitucionales se ha convertido en un aspecto clave para las estrategias de innovación y desarrollo territorial (Salom y Albertos, 2009; Caravaca y González, 2009, Méndez et al., 2006; entre otros).

A pesar de la variedad de tipologías, podemos conceptualizar estas instituciones como organismos orientados localmente, cuya función esencial es proporcionar un conjunto de servicios de apoyo a las empresas ubicadas en el distrito (Molina, 2005). En sus trabajos, autores como Baum y Olivier (1992) y Cooke $(1999,2002)$ revisan un conjunto de experiencias sobre la comunidad de intereses y la intensa colaboración entre empresas e instituciones locales para diseńar soluciones para retos 
de distinto perfil. Las evidencias empíricas sobre el efecto positivo de la actividad institucional en diversos aspectos del desempeño del distrito y sus empresas, también ha sido ampliamente contrastado (Almeida y Kogut, 1999; Belso, 2006; Salom y Albertos, 2006, entre otros). Universidades, centros de investigación, centros formativos, agencias de desarrollo u organizaciones profesionales y empresariales son casos de instituciones en principio orientadas localmente, pero hoy abiertas a establecer vínculos en los ámbitos intersectorial o supralocal donde acumulan nuevas oportunidades que se procesan y transmiten al tejido empresarial del distrito industrial.

El enfoque inicialmente asumido en la Comunidad Valenciana entronca con aquellas propuestas teóricas que reconocen el ámbito local como un entorno innovador y generador de crecimiento, en el que las empresas aglomeradas se benefician de múltiples externalidades y recursos específicos. Dichas externalidades, en especial las relacionadas con el conocimiento, están confinadas en el distrito industrial, y las conexiones con el exterior son esporádicas o prácticamente inexistentes (Boschma y Lambooy, 2002). La existencia de una red densa de relaciones interorganizacionales de tipo local permite intensificar el aprendizaje colectivo y la actividad innovadora de los agentes implicados (Méndez, 2006b; Salom, 2003). Consecuencia de su rol de liderazgo y su inserción en un contexto estratégico y relacional amplio, las instituciones se transforman en auténticas dinamizadoras de la actividad innovadora del distrito y un elemento esencial para la viabilidad de la aglomeración empresarial (Jessop, 2001). Las fronteras del distrito encierran las redes por las que fluye el conocimiento y las instituciones centran su actividad en favorecer la transferencia de conocimiento entre los distintos componentes de la red local. En suma, los efectos de desbordamiento y del aprendizaje están íntimamente ligados al espacio.

Semejante unión entre territorio, redes y conocimiento no deja de reconocer la relevancia de las instituciones locales a la hora de facilitar la generación de innovaciones en el ámbito local. En la actualidad la innovación se entiende como un proceso interactivo de aprendizaje donde participan múltiples actores y un amplio medio institucional (Salom, 2003). Sin embargo, el reciente tránsito experimentado hacia un distrito caracterizado por redes abiertas al exterior pone en cuarentena algunas convicciones propias de las premisas marshallianas. El fenómeno de la globalización y la intensidad competitiva demanda la consolidación de contactos externos al distrito capaces de cubrir aquellas deficiencias en ciertos apartados de gestión, marketing, comunicación o actividades de $\mathrm{I}+\mathrm{D}+\mathrm{i}$ que el desarrollo interno se muestra incapaz de cubrir de manera unilateral (Camuffo y Grandinetti, 2005). Como apuntan diversas inves- 
tigaciones (Molina et al., 2002; Molina, 2005; Belussi et al., 2008), una estructura de redes de perfil local facilita la rápida diseminación de conocimiento en el seno del distrito, aunque puede llegar a entorpecer la llegada de innovaciones radicales debido a su carácter redundante. ${ }^{2}$

Para romper esta dinámica redundante y desarrollar su capacidad de competir, las empresas establecen canales para absorber conocimientos y comparten experiencias con otras firmas, consultoras o asociaciones ubicadas fuera del distrito. Los estudios empíricos realizados por Morrison (2008) y Guliani y Bell (2005) demuestran cómo algunas empresas ubicadas en el distrito tienen intensas conexiones con organizaciones localizadas más allá de las fronteras del mismo. En consonancia con esta nueva realidad, la teoría de redes apuesta por caracterizar las relaciones entre los agentes más como estructuras sociales que por su dimensión espacial. Esta perspectiva asume la densidad de las redes sociales entre los agentes ubicados en el distrito, pero reconoce la posibilidad de su extensión más allá de los límites del mismo. La distancia geográfica se convierte en una barrera a considerar, bien es cierto que minimizada por la contribución de las nuevas tecnologías a la interconexión con agentes económicos no locales.

Estudios empíricos como los desarrollados por Molina (2005) reflejan cómo las instituciones locales también han superado su tradicional dimensión local, estableciendo múltiples contactos con organismos y centros de investigación pertenecientes a otros países, sectores o distritos. Esta nueva práctica permite adquirir experiencias que, tras ser procesadas, se podrán difundir en el ámbito del distrito. En esencia, las instituciones se transforman en una suerte de intermediarios, ya que captan conocimientos de valor y oportunidades de negocio procedentes del exterior y posteriormente las diseminan entre las empresas utilizando sus densas redes locales. Siguiendo a Pilotti (2000), se trata de metaorganizadores del sistema local con la función específica de conectar la multiplicidad de tecnologías, la heterogeneidad de organizaciones y las transacciones internas alcanzadas mediante la dinámica colaboración-cooperación.

Es en este apartado donde la actuación pública y la actividad de instituciones privadas desempeñan un rol esencial, ya que la escasez de recursos y el reducido tamaño de las empresas del distrito dificultan asumir los costos derivados del escaneado y la evaluación unilateral de las oportunidades e innovaciones detectadas en el entorno exterior. A pesar de este papel clave, es escasa la investigación empírica realizada sobre la base que otorga la perspectiva de las redes institucionales y el capital social,

${ }^{2}$ Sólo estudios recientes recogen la importancia de las redes extralocales frente a la tradicional predilección por las redes locales (Salom, 2003). 
salvo excepciones como los trabajos de Molina (2005) o Molina et al. (2002), y se reduce a la constatación de la existencia de ciertas instituciones más o menos formales en el seno del distrito (Martin y Sunley, 2003; Salom y Albertos, 2006).

En suma, hoy en día la competitividad del distrito no sólo proviene de las capacidades desarrolladas desde una perspectiva endógena y asentadas en infraestructuras de calidad, servicios de apoyo, eficiencia de las redes locales, flujos de información entre las empresas del distrito o un sistema científico-tecnológico profundamente arraigado en el territorio. Parece imprescindible la inserción del distrito en un entorno innovador más amplio. Para ello es necesaria la participación activa de los agentes económicos y sociales implicados en el desarrollo territorial con el fin de, por un lado, interactuar con instituciones públicas y privadas de orden superior al local, para contrastar y enriquecer su acervo de conocimiento con experiencias obtenidas allende los límites del distrito; y, por otro, dispersando todo este bagaje entre las empresas ubicadas en su entorno local. De ahí que se haga imprescindible que las instituciones locales, sin abandonar su tradicional enfoque local, asuman la conveniencia de interactuar cada vez más con ámbitos no locales y se conviertan en intermediarias entre el entorno externo y el espacio geográfico más próximo.

\section{Metodología}

En la línea de lo expuesto hasta ahora, nuestro trabajo pretende contrastar la capacidad de las instituciones locales públicas de generar valor para las empresas del distrito industrial mediante la obtención de conocimientos externos, y su posterior transformación y difusión en el entorno local. Para conseguir este objetivo, estudiamos el distrito industrial del Vinalopó, una aglomeración de empresas dedicadas al calzado situada al sur de la Comunidad Valenciana.

El trabajo de campo se llevó a cabo en dos fases. En una etapa inicial, sirviéndonos de fuentes secundarias, analizamos la trayectoria y realizamos un diagnóstico del distrito, también identificamos las instituciones que operan activamente en el mismo. Así, siguiendo las premisas contenidas en Alonso y Méndez (2000), Caravaca et al. (2005) y Salom y Albertos (2006) elaboramos un directorio de las principales instituciones públicas y las organizaciones socioeconómicas con capacidad de dinamizar o promover proyectos en el territorio. Entre las instituciones públicas incluimos las diferentes administraciones locales, regionales o nacionales con competencias sobre el territorio; mientras que por organizaciones socioeconómicas entendemos los centros de investigación, institutos, centros de formación especializada, centros de servicios o asociaciones empresariales. 
En la siguiente etapa se realizó un amplio número de entrevistas en profundidad a tres grupos poblacionales: empresarios, expertos y representantes de distintas instituciones. Para las mismas se emplearon tres instrumentos diseñados ad hoc por el equipo investigador. Uno para las entrevistas a las instituciones de apoyo locales y regionales, otro para los empresarios representativos del sector y, finalmente, el específico para los expertos. En el caso de los expertos e instituciones, la muestra se seleccionó por juicio sobre la base de la información secundaria, la amplia experiencia previa del equipo investigador y en función de los criterios empleados por Urbano (2003), Aponte (2002) o Gómez et al. (2004): a) que exista representación de instituciones públicas y privadas, $b$ ) que haya organismos con servicios y programas de índole económica y no económica, y c) que se cuente con organismos que ofrezcan servicios a colectivos específicos y generales. Por lo que respecta a la muestra de empresarios, también se diseńó con las premisas derivadas de la información secundaria y la experiencia del equipo investigador y con criterios previamente establecidos: a) que la empresa se ubicase en el sector y el distrito objeto de estudio, b) que hubiese representación de unidades productivas situadas en los extremos y en fases intermedias de la cadena de valor, y $c$ ) que el empresario presentase una trayectoria relevante y de reconocido prestigio.

\section{Evidencia empírica}

Tras una breve caracterización del distrito industrial escogido, a lo largo de este apartado presentamos los dos grupos de resultados derivados de la investigación. El primero recoge las evidencias relacionadas con el análisis descriptivo de las redes socioinstitucionales del distrito industrial del Vinalopó. En particular, se analizan propiedades de las redes sobre la base de atributos como la densidad, grado de centralización o rasgos de sus actores. Mientras el segundo grupo tiene un perfil cualitativo e intenta evidenciar las relaciones de las instituciones locales con el exterior. Para ello nos servimos del análisis de los casos de la Federación de Industrias del Calzado (FICE) y del Instituto Tecnológico del Calzado (Inescop).

\subsection{El distrito industrial del Vinalopó en perspectiva}

El modelo de organización industrial asentado en los distritos industriales ha sido adoptado por un abanico muy amplio de sectores económicos con predominio de pequeñas y medianas empresas. Entre estos sectores, el calzado ocupa un lugar preeminente en países como Italia, Portugal, México o Brasil. España, uno de los principales productores en el mundo, no es una excepción. Así, un amplio grupo de autores han reconocido la 


\section{Mapa I \\ Ubicación geográfica de las instituciones locales en la provincia de Alicante}

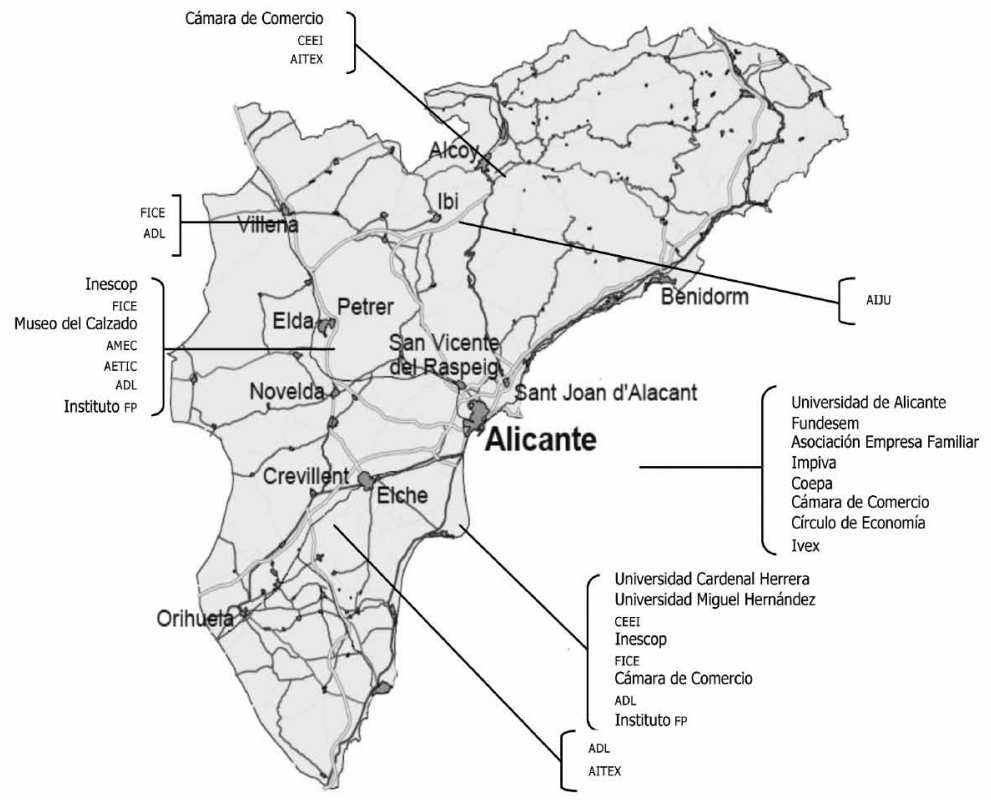

Fuente: Elaboración propia.

existencia de distritos industriales en diversas zonas geográficas españolas: la Comunidad Valenciana, La Rioja, Islas Baleares, Aragón, Andalucía o la región de Murcia (Boix y Galletto, 2006; Tomás y Such, 1997; Climent y Méndez, 2002; Giner y Santa María, 2002, entre otros).

Como se muestra en el mapa I, el distrito zapatero del Vinalopó se localiza en el sur de la Comunidad Valenciana y se articula esencialmente a lo largo del eje que supone el río del mismo nombre, en concreto en las poblaciones de Elche, Crevillente, Elda, Petrer y Villena. Esta industria tiene su origen en el siglo XIX con la fabricación de alpargatas, ${ }^{3}$ puesto que el calzado de piel fue una alternativa minoritaria hasta bien entrado el siglo pasado (Miranda, 1998). De hecho, no fue hasta el primer tercio del siglo xx cuando se lleva a cabo la mecanización y el desarrollo del sector, impulsado por el aumento del consumo y la difusión de innova-

${ }^{3}$ Ampliamente utilizada en el medio rural, la alpargata es un tipo de calzado textil con suela de esparto o cáńamo, que se asegura por simple ajuste o mediante el empleo de cintas. 


\section{Cuadro 1 \\ Principales macromagnitudes del sector calzado}

\begin{tabular}{|c|c|c|c|c|c|c|c|c|c|c|c|c|}
\hline & \multicolumn{3}{|c|}{ Empresas } & \multicolumn{3}{|c|}{$\begin{array}{c}\text { Exportaciones } \\
\text { (miles de unidades) }\end{array}$} & \multicolumn{3}{|c|}{$\begin{array}{c}\text { Importaciones } \\
\text { (miles de unidades) }\end{array}$} & \multicolumn{3}{|c|}{ Empleados } \\
\hline & 2000 & 2006 & $\%$ & 2000 & 2006 & $\%$ & 2000 & 2006 & $\%$ & 2000 & 2006 & $\%$ \\
\hline & & & & & & & & & & & & \\
\hline Valenciana & 3,317 & 2,967 & -10.5 & 99,529 & 52,733 & -47 & 30,285 & 134,424 & 4344 & 35,386 & 622,999 & -35 \\
\hline España & 5,054 & 4,520 & -10.6 & 143,599 & 95,336 & -33.6 & 81,350 & 296,480 & 264 & 47,025 & 533,521 & -29 \\
\hline
\end{tabular}

Fuente: Elaboración propia con base en Instituto Nacional de Estadística (2007a, 2007b).

ciones fruto de la llegada de empresas procedentes del exterior. El intervencionismo del modelo autárquico obstaculizó el despegue a lo largo de los años cincuenta y sesenta. La escasa renovación tecnológica, una organización productiva rudimentaria y la reducida calidad del producto desembocaron en una competitividad asentada en la baja remuneración salarial (Miranda, 2008).

Durante los años setenta la realidad del distrito industrial dio un giro radical con la llegada de empresas comerciales procedentes de Estados Unidos. Se implantó un modelo caracterizado por una externalización de actividades clave (diseño, logística o comercialización) y una orientación a labores estrictamente productivas. Esta dependencia se mantuvo hasta la segunda mitad de los ochenta, cuando el comienzo del peregrinaje de estas comercializadoras hacia países con costos bajos empujó a los emprendedores a implementar estrategias más o menos imaginativas, que iban desde el refugio en la economía sumergida hasta mejoras en producto, procesos productivos o gestión (Tortajada et al., 2005). El futuro no nos permite establecer buenos augurios para el sector, como evidencian las macromagnitudes del cuadro 1 . Sin embargo, no es menos cierto que desde los años noventa los empresarios han conseguido capear un marco económico claramente desfavorable como consecuencia de la globalización, los cambios en la distribución o las propias carencias estructurales del sector.

Actualmente, el distrito se compone de Pymes aglomeradas en un espacio geográfico inferior a $50 \mathrm{~km}$ de diámetro y frecuentemente de propiedad familiar, $89 \%$ tiene menos de 20 empleados según datos del Directorio Central de Empresas (Dirce). Cada unidad productiva se suele especializar en una actividad concreta de la cadena de valor. Por tanto, no se trata únicamente de una especialización basada en partes del proceso productivo (por ejemplo, aparado o corte), sino también en la prestación de servicios como diseño o patronaje. La imbricación de las empresas en el entorno social es intensa. Es complejo encontrar algún club, patronato, sociedad, institución benéfica, asociación e incluso el 


\section{Figura I \\ El entorno del distrito del Vinalopó}

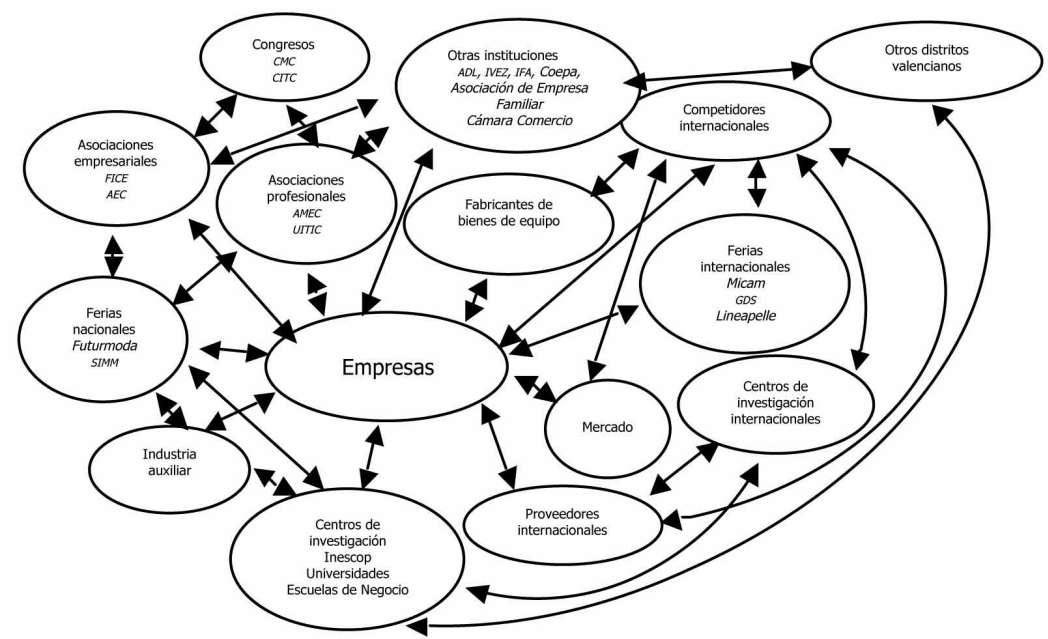

Fuente: Elaboración propia con base en Albors y Molina (2001), Climent y Méndez (2002), Tortajada et al. (2005), Tomás et al. (1997) e Ybarra y Santa María (2005).

mismo Consejo Social de la Universidad, que no tenga empresarios del sector al frente.

La complejidad del entorno y la multiplicidad de agentes que operan en el seno del distrito se muestran en la figura I. Se observa una intensa relación entre empresas productoras, industria auxiliar e instituciones locales (asociaciones de diseñadores, técnicos y empresarios, así como administraciones públicas y cámara de comercio). Con esta realidad relevante, lo verdaderamente esencial para la supervivencia del distrito industrial es la interacción de algunos actores locales con otros distantes geográficamente, gracias a la participación en proyectos y eventos multisectoriales o multinacionales. Por un lado, vemos que las empresas mantienen flujos comerciales y de información estables con proveedores ubicados en distintas regiones espańolas, países o sectores económicos. Por otro, instituciones locales como asociaciones y centros de investigación se relacionan cada vez más con organizaciones procedentes de otros ámbitos geográficos y sectoriales. En esencia, en ambos casos se observa una interacción de los actores locales con otros no locales (incluso procedentes de otros sectores). Esto facilita la aprehensión de conocimientos novedosos capaces de desembocar en valiosas innovaciones estratégicas o tecnológicas.

En el cuadro 2 (ver anexo) se recoge un listado exhaustivo de las diferentes instituciones con distintos grados de relevancia y participación en las actividades del distrito. El mapa I evidencia una implantación gene- 
ralizada de las instituciones y organizaciones en todo el distrito, aunque se nota una concentración en Alicante (capital administrativa de la provincia) y los dos núcleos urbanos más importantes del distrito (Elche y Elda). En términos generales, su labor podríamos estructurarla en tres ámbitos muy diferenciados. En primer lugar, actividades ligadas estrictamente al concepto marshalliano, como actividades de I+D+i, consolidación de redes empresariales, formación especializada o servicios técnicos a empresas del distrito. En segundo lugar, examen del entorno externo y transmisión de la información obtenida en las empresas del distrito. Mediante esta tarea, se convierten en catalizadoras de conocimientos alcanzados fuera del distrito hacia las empresas pertenecientes al mismo. En tercer lugar, representan una vía de salida al exterior de aquellas innovaciones técnicas o de gestión desarrolladas en el ámbito local.

\subsection{Las redes socioinstitucionales en el distrito industrial del Vinalopó}

Sirviéndonos de la información secundaria y los resultados de las entrevistas en profundidad, construimos una matriz binaria de relaciones interinstitucionales en el distrito industrial del Vinalopó. En esta matriz reflejamos la existencia de cooperación entre dos actores mediante el valor uno, la ausencia de relaciones de cooperación con un cero. Asumimos la existencia de cooperación entre dos instituciones en cada uno de los siguientes casos: $a$ ) existen convenios o acuerdos explícitamente reconocidos; $b$ ) hay programas o actividades organizadas de forma conjunta, y c) la existencia de cooperación se menciona a lo largo de alguna de las entrevistas realizadas o alguna fuente de información secundarias (por ejemplo, prensa local o prensa especializada).

Una vez obtenida la matriz, la técnica de análisis de redes sociales a través del programa de tratamiento de datos relacionales Ucinet 6, nos permitió determinar las características estructurales de las redes de actores a partir de varios indicadores: densidad, distancia geodésica, diámetro de red y grado de centralidad. Finalmente, el paquete informático también nos dio la posibilidad de construir el grafo de la red, donde se plasmaron las posiciones de los distintos actores y las características de las relaciones.

Un aspecto destacable de nuestros resultados es la importante proporción de relaciones existentes en el total de relaciones posibles: $52.46 \%$. La variabilidad media de un elemento a otro es 0.49 , por lo que hay relativamente una gran cantidad de variación en las relaciones entre los actores. ${ }^{4}$ El corto camino geodésico alcanzado $(1,514)$ y el diámetro de

\footnotetext{
${ }^{4}$ El carácter simétrico de nuestra matriz impide profundizar en el modo en que cada actor está inmerso en la densidad global.
} 
la red (3) corroboran la densidad y compacidad de nuestra red socioinstitucional, sugiriendo una rápida transferencia de información y un uso más eficiente de los recursos. Muchas instituciones y organizaciones están conectadas por más de un camino, con lo cual podemos asumir inicialmente que no existirá un actor poderoso frente a los restantes.

En términos generales, esta elevada densidad se encuentra en línea con la obtenida por Salom y Albertos (2006) para el distrito cerámico de Castellón, y aleja cualquier duda sobre la intensidad de las relaciones en el conjunto de la red socioinstitucional analizada. Bien es cierto que en nuestro análisis del distrito del Vinalopó, la densidad alcanzada es ligeramente superior debido a la inclusión de varias instituciones muy interrelacionadas (como Ivex-Icex o los diferentes institutos tecnológicos).

La medida del grado de centralidad indica el número de actores a los que cada uno está directamente unido, ofreciendo una idea del peso específico de la institución en el conjunto de la red socioinstitucional. Los resultados indican que existen 16 instituciones con un índice de centralidad superior a 50\%. Entre ellas, los institutos tecnológicos, la Cámara de Comercio de Alicante, FICE, universidades y los institutos para el fomento del comercio exterior alcanzan un grado de centralidad mayor de $65 \%$. Por tanto, son muchas las instituciones que impulsan el desarrollo de actividades en el distrito industrial del Vinalopó y, por tanto, se puede mantener que la estructura de la red se caracteriza por un policentrismo consolidado. Frente a este grupo, el Círculo de Economía, los Institutos de Formación Profesional, la Asociación del Terciario Avanzado, Fundesem y los dos congresos sectoriales reflejan un grado de centralidad relativamente bajo, inferior a 30 por ciento.

El grafo de la red socioinstitucional que se muestra en la figura II, nos permite corroborar el elevado número de interrelaciones entre los actores locales y el marcado policentrismo de la estructura obtenida. Asimismo, el gráfico establece las posiciones que ocupan los actores y las líneas que marcan y determina las posiciones de cada uno de los actores de la red. En líneas generales, hemos de resaltar una cierta acumulación de organizaciones e instituciones de carácter multisectorial (gris) en una zona específica. También se observa la mayor proximidad de la Universidad Miguel Hernández (ubicada en el centro del distrito industrial) a las instituciones y centros de investigación específicos del sector. Mientras la Asociación de diseñadores (Amec) presenta una posición más centrada, las instituciones de técnicos (UITIC), los congresos técnicos (WFC o ITFC), los centros de formación profesional y las escuelas de negocios (Fundesem) muestran posiciones periféricas. 


\section{Figura II}

\section{Grafo de las relaciones socioinstitucionales en el distrito industrial del Vinalopó}

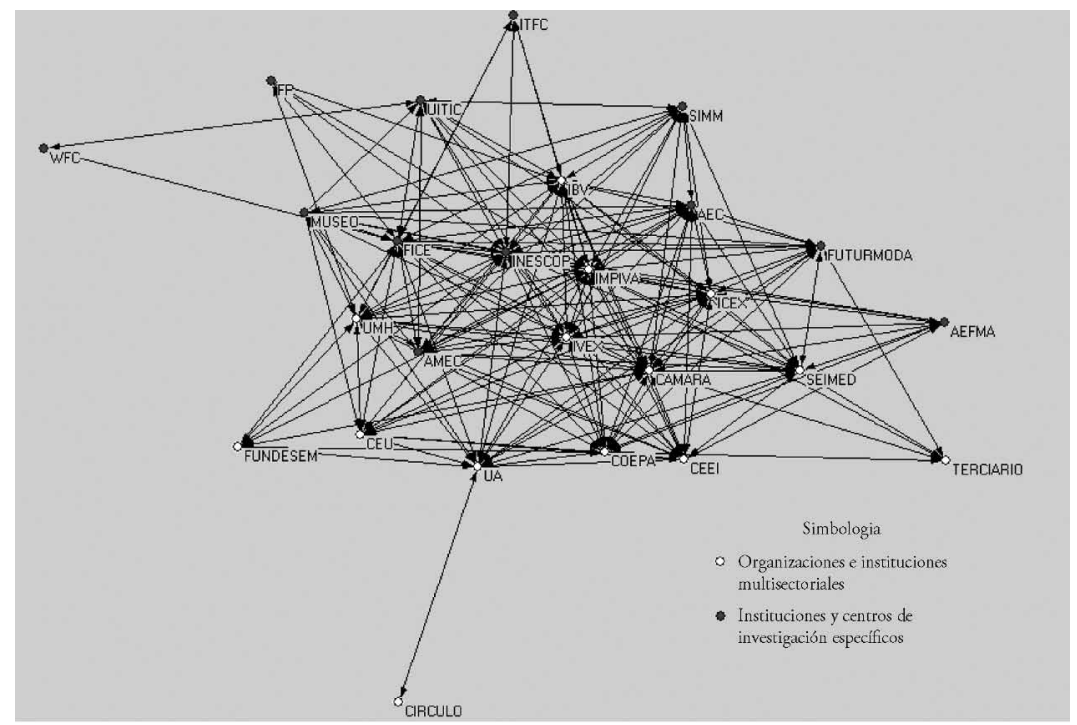

Fuente: Elaboración propia.

\subsection{Las instituciones locales en la era de la globalización: FICE e Inescop}

Como mencionamos, sobre la base de su propia experiencia y de los conocimientos acumulados a partir de las actividades de empresas locales, las instituciones locales tradicionalmente han ofrecido servicios de apoyo a las empresas del calzado en campos relacionados con el ámbito técnico, formativo, del medio ambiente o de $\mathrm{I}+\mathrm{D}+\mathrm{i}$. Durante las dos últimas décadas, con la aceleración del proceso de globalización y la apertura de las redes del distrito, las instituciones profundizan sus relaciones con el entorno externo al distrito mediante participación en congresos, colaboración en proyectos de investigación y prestación de servicios en el ámbito regional, nacional e internacional. Como ocurre en otros distritos (Molina, 2005; Molina et al., 2002), a través de estos contactos las instituciones absorben conocimientos y experiencias del exterior, para después difundirlas en la distrito asiduamente a empresas líderes en fabricación y/o distribución de calzado. En definitiva, exploran las potenciales ventajasoportunidades más allá de las fronteras del distrito y facilitan la explotación de las mismas en el entorno local (Belussi et al., 2008). 


\subsubsection{Federación de Industrias del Calzado Español}

Entre el conjunto de instituciones mencionadas, seleccionamos FICE e Inescop para profundizar en nuestro análisis. Las razones para esta elección radican, por un lado, en el amplio conocimiento obtenido en investigaciones previas relacionadas con nuestro ámbito de estudio (Tortajada et al., 2005; Tomás et al., 2000), su papel como proveedores de valor para el conjunto del distrito, su apertura e integración en redes exteriores, y su centralidad refleja el análisis cuantitativo y el grafo de red (figura II).

La Federación de Industrias del Calzado Español (FICE), creada en 1977, agrupa 12 asociaciones de empresas distribuidas en las principales zonas productivas del país y se integra como miembro de pleno derecho en hasta 30 comisiones y organizaciones, entre las que destacan: la Confederación Europea del Calzado (CEC), la Confederación Española de Organizaciones Empresariales (CEOE), la Confederación Española de la Pyme (Cepyme), la Confederación Española de Curtidores (CEC-Fecur) o la Asociación Española de Empresas de Componentes del Calzado (AEC). Finalmente, tiene acuerdos de colaboración con el Instituto de la Mediana y Pequeña Empresa Valenciana (Impiva), el Instituto Valenciano de la Exportación (Ivex), la Institución Ferial de Madrid (Ifema), la Institución Ferial de Alicante (IFA), el Instituto Tecnológico del Calzado y Conexas (Inescop) y el Instituto Tecnológico de Biomecánica (IBV).

Sus actividades abarcan prácticamente todos los ámbitos de la empresa, pero tiene un peso muy significativo el asesoramiento, la promoción de la actividad internacional de las empresas y el establecimiento de relaciones y contactos con otras asociaciones e instituciones. En el cuadro 3 (ver anexo) se muestran los proyectos más importantes llevados a cabo por la FICE en los últimos años. Entre ellas destacamos la apuesta por la innovación, el fomento de la adopción de modernas técnicas de gestión, el establecimiento de contactos estables con socios e instituciones no ubicadas en el distrito del Vinalopó y la frecuente interacción con empresas de varios distritos industriales del calzado.

El papel de la FICE en la creación de valor para las empresas del distrito radica en varios ámbitos. En primer lugar, monitorea y acumula innovaciones y buenas prácticas desplegadas por empresas o instituciones externas al distrito. No sólo procedentes del mismo sector industrial, sino también de otros sectores económicos. Por ejemplo, la inclusión de la FICE en la SIMM ${ }^{5}$ representa un medio de importación de conocimientos del conjunto del sistema de la moda, evidentemente encabezado por

\footnotetext{
${ }^{5}$ La Semana Internacional de la Moda de Madrid agrupa un conjunto de eventos de diversa índole, relacionados con el sector de la moda. Se realiza semestralmente, y entre otros recoge ferias del calzado o la confección.
} 
los grandes grupos de distribución del textil-confección. En segundo lugar, proporciona apoyos a las pequeñas empresas en términos de servicios especializados relacionados con actividades de alto valor añadido, como marketing, la promoción o la apuesta por comportamientos estratégicos avanzados (deslocalización). En tercer lugar, presta servicios de asesoría y proporciona información en ciertos capítulos donde las empresas no siempre parecen estar dispuestas en invertir debido a su escasa sensibilización o su tamaño reducido. Por ejemplo, información para la toma de decisiones, gestión ambiental, gestión de la innovación, formación u obtención de subvenciones. En cuarto lugar, representa un canal mediante el cual se transmiten los conocimientos adquiridos en el seno del distrito.

\subsubsection{Instituto Tecnológico del Calzado y Conexas}

El Instituto Tecnológico del Calzado y Conexas (Inescop) es una organización de servicios para las industrias de calzado, sus conexas y auxiliares, formada por las propias empresas para abordar de forma colectiva actividades tecnológicas de interés sectorial que no se pueden llevar a cabo individualmente. Inescop inició sus actividades en 1971 y en la actualidad cuenta con más de 600 empresas asociadas y más de 100 personas empleadas. En el seno del consejo rector de la institución encontramos un conjunto de empresas líderes en el sector, representantes de las administraciones públicas (comunidades autónomas, administración central y administraciones locales) y centros de investigación. Se trata, por tanto, de un centro de innovación y tecnología sectorial que proporciona servicios directos, transfiere conocimientos e investiga sobre temas de interés general. Su rigurosidad y capacidad de generación/transmisión de conocimiento queda ampliamente demostrada dada su pertenencia al consejo de dirección de la Fundación Española para la Ciencia y la Tecnología (Fecyt), al Patronato del Observatorio de Prospectiva Tecnológica Industrial (opTI), a la Unión Europea de Institutos de Investigación del Calzado (Euris), a la Asociación Española de Normalización y Certificación (Aenor) o la Entidad Nacional de Acreditación (Enac).

Las actividades de apoyo desarrolladas por el instituto abarcan las necesidades científico-técnicas de las empresas del sector, donde destaca sobre todo: la comprobación y el aseguramiento de la calidad, la organización de los procesos productivos, el estudio de los materiales, el desarrollo e incorporación de tecnologías avanzadas, la formación de recursos humanos, la información y documentación especializada, las relaciones con el medio ambiente, el diseño industrial, las tendencias de moda y la investigación aplicada en general. La prestación de este amplio conjunto 
de tareas demanda aunar esfuerzos con instituciones similares y/o complementarias, e incluso acuerdos de colaboración con empresas del sector. Frecuentemente esta cooperación se establece con universidades, centros de investigación, asociaciones empresariales, empresas, etc., en el marco que suponen los proyectos auspiciados por programas regionales, nacionales y europeos, como muestra el cuadro 4 (ver anexo).

De acuerdo con estudios previos realizados para otros sectores (Molina et al., 2002), Inescop contribuye de manera esencial a que las empresas superen un conjunto de barreras de cara a su integración en redes externas. Algunas actividades de alto valor ańadido, por ejemplo el I+D, suponen una inversión de recursos demasiado elevada para el tamaño medio de las empresas del sector del calzado en general, y del distrito del Vinalopó en particular. Inescop contribuye a franquear esta barrera obteniendo en el interior o exterior financiación pública, recursos humanos adecuados o un pool de empresas interesadas en invertir en un mismo proyecto. En ocasiones, a pesar de tener los recursos necesarios y debido a su elevado índice de especialización en eslabones concretos de la cadena productiva, una empresa no se encuentra en disposición de acometer actividades innovadoras que demandan un conocimiento global de la problemática del sector. El instituto tecnológico actúa como acumulador de experiencias del conjunto de la cadena de valor del sector, o como coordinador de conocimientos procedentes de varios agentes económicos localizados dentro o fuera del distrito. Por último, la transferencia de conocimientos desde el exterior a la empresa local, resulta menos costosa e implica menores riesgos en la medida que se hace vía una institución y no directamente (ahorros en contratos, obtención de información, búsqueda de socios/colaboradores internacionales, etcétera).

\section{Conclusiones, limitaciones e implicaciones}

A lo largo de la presente investigación hemos tratado de demostrar cómo las instituciones públicas y privadas localizadas en el distrito del Vinalopó contribuyen de manera esencial en la capacidad de competir de las empresas del sector del calzado, mediante su intermediación entre el entorno local y el no local. Aplicando la aproximación de la teoría de redes y del capital social, recientemente empleada en trabajos de perfil similar (Molina et al., 2002; Molina, 2005 o Belussi et al., 2008), podemos afirmar que: a) las evidencias cuantitativas obtenidas corroboran la densidad de la red socioinstitucional del distrito del Vinalopó; b) los resultados del análisis cualitativo confirman el papel de intermediación desarrollado por dos instituciones del distrito industrial (FICE e Inescop), y su generación 
de valor para las empresas locales. A continuación sintetizamos las principales aportaciones, implicaciones y limitaciones del estudio.

En primer lugar, como consecuencia de la intensa competencia procedente de países con mano de obra barata, las empresas y las instituciones públicas y privadas ubicadas en el distrito se han visto obligadas a establecer un número creciente de contactos en el exterior, en busca de herramientas capaces de generar ventajas competitivas. Dado que el ámbito local de forma unilateral parece incapaz de proporcionar recursos y conocimientos suficientes para asegurar la innovación y competir en un entorno altamente globalizado, las instituciones se han integrado en redes que superan los límites del propio distrito, con el afán de conseguir nuevos conocimientos, oportunidades de negocio y compartir experiencias con otros agentes innovadores, como universidades, empresas, institutos tecnológicos o centros de investigación no locales.

Esta evidencia contrastada mediante las dos organizaciones analizadas, implica un cambio en la estructura y la dimensión espacial de las redes en que ambas se han encontrado inmersas a lo largo de los años. Inicialmente, la importancia de los contactos en el ámbito local era muy superior al peso de las relaciones no locales. Incluso hoy, como demuestra nuestro análisis cuantitativo de la red socioinstitucional, la densidad relacional entre las instituciones es considerable. Sin embargo, a medida que el conjunto del distrito del Vinalopó ha ido superando diversas fases de su ciclo de vida, adentrándose en un entorno globalizado y apuntando un cierto declive, la relevancia de los eslabones no ubicados en un ámbito geográfico próximo es cada vez mayor. Se produce así un cierto paralelismo entre la evolución de la estructura de la red y del conjunto del distrito (Iammarino y McCann, 2006).

En segundo lugar, ambas instituciones generan valor para las empresas del distrito. Por un lado, siguiendo la línea tradicional de su actividad, mantienen un amplio número de servicios de apoyo en materias como, sin ánimo de ser exhaustivos, los ensayos de laboratorio, el asesoramiento en diversas materias o la formación. Por otro lado, fruto de su interacción con agentes no locales, ambas instituciones recopilan conocimientos en nuevas tecnologías vinculadas a diferentes fases de la cadena de valor (producción, logística, comercialización o gestión) o estrategias (por ejemplo, la deslocalización), para posteriormente trasladarlas al tejido productivo local mediante redes ya largo tiempo consolidadas. Se confirma de este modo el papel de intermediarias (Molina et al., 2002) o metaorganizadoras (Belussi et al., 2008) en el ámbito del distrito detectadas en estudios previos.

En tercer lugar, la proximidad continúa representando un factor fundamental para el establecimiento de relaciones estables y basadas en la 
confianza mutua. La distancia geográfica, cultural o social ralentiza la creación inmediata de esos vínculos entre agentes locales y no locales. Si bien es cierto que el ciberespacio y las nuevas tecnologías han contribuido a minimizar muchas de las reticencias, todavía persisten ciertos resquemores por parte de las empresas locales para interactuar plenamente con agentes externos. A la luz de los resultados obtenidos, mediante su papel de intermediación, las instituciones parecen estar ejerciendo como un transmisor de plena confianza debido a su proximidad al sistema local y su creciente integración en el entorno externo. La densa red socioinstitucional del distrito permite la difusión eficiente entre los actores locales de aquellos conocimientos importados por las organizaciones empresariales o centros de investigación. Por un lado, las empresas pueden acceder a estos nuevos conocimientos vía varios actores de la red socioinstitucional, gracias al elevado número de conexiones. Por otro lado, las mismas instituciones se benefician de los conocimientos importados por otros organismos a la hora de diseñar programas, poner en marcha proyectos o desarrollar líneas de trabajo.

En cuarto lugar, algunas instituciones y organizaciones propias del sector (por ejemplo, asociaciones de técnicos o congresos) quedan relegadas a posiciones relativamente periféricas en el conjunto de la red. En efecto, este resultado puede estar determinado por la no inclusión de actores como empresas productoras y proveedores. Sin embargo, conviene reflexionar en la necesidad de fomentar el desarrollo y la integración de estos actores. Una mayor implicación de los mismos puede contribuir a una mejor difusión de conocimientos y al aumento de la capacidad innovadora del distrito.

Desde una perspectiva de actuación pública, las implicaciones de nuestros resultados son evidentes. Por un lado, es papel de la actividad pública continuar fomentando la integración de las instituciones locales en el entorno externo en pos de aprehender conocimientos generados allende las fronteras del distrito y hacer que las empresas locales los absorban. De este modo no sólo se logra incrementar la capacidad innovadora de las empresas ubicadas en el distrito industrial, sino también evitar cualquier situación de bloqueo en la evolución de la aglomeración empresarial. No debemos olvidar que la rápida diseminación de los conocimientos importados requiere un entorno de confianza, de ahí que las autoridades (vía instituciones) deban contribuir a conservar las densas relaciones locales forjadas durante ańos. Por otro lado, la densa red socioinstitucional permite una amplia difusión de la información importada entre todos los actores de la misma. Los conocimientos adquiridos por los intermediarios o metaorganizadores se diseminan rápidamente entre todas las instituciones (públicas o privadas), contribuyendo de este modo 
a mejorar el perfil de los programas y actuaciones implementadas por las mismas. En suma, los responsables en materia de política económica deben asumir la conveniencia de seguir cultivando este papel de intermediación ejercido por instituciones locales clave. Si bien es cierto que no deben relegar el impulso de las nuevas tecnologías como herramientas clave para construir redes no locales por parte de las empresas del distrito.

No debemos dejar de mencionar las limitaciones derivadas de la presente investigación. Se trata de un estudio centrado en la realidad de un distrito y sector industrial maduro. Es probable que los resultados obtenidos varíen sensiblemente en caso de modificar el perfil del sector industrial o la fase evolutiva del propio distrito. La metodología y las fuentes utilizadas demandan un contraste empírico más profundo y con un enfoque más dinámico. Especialmente se debe tener en cuenta la necesidad una medición más elegante de las relaciones entre los distintos actores, así como la inclusión de algunos relegados en este trabajo. Por último, más allá de las líneas de investigación abiertas por la metodología o el distrito seleccionado, futuros trabajos deben prestar atención especial a las potenciales dificultades derivadas de la creciente apertura de las redes y del papel de intermediación ejercido por las instituciones locales. Por ejemplo, la colaboración implica compartir conocimientos valiosos alcanzados en el distrito con otros sistemas potencialmente competidores.

\section{Agradecimientos}

Los autores agradecen la labor del editor, los comentarios realizados por los dos dictaminadores y la financiación del Ministerio de Ciencia e Innovación en el marco del proyecto ECO2010-20557. 


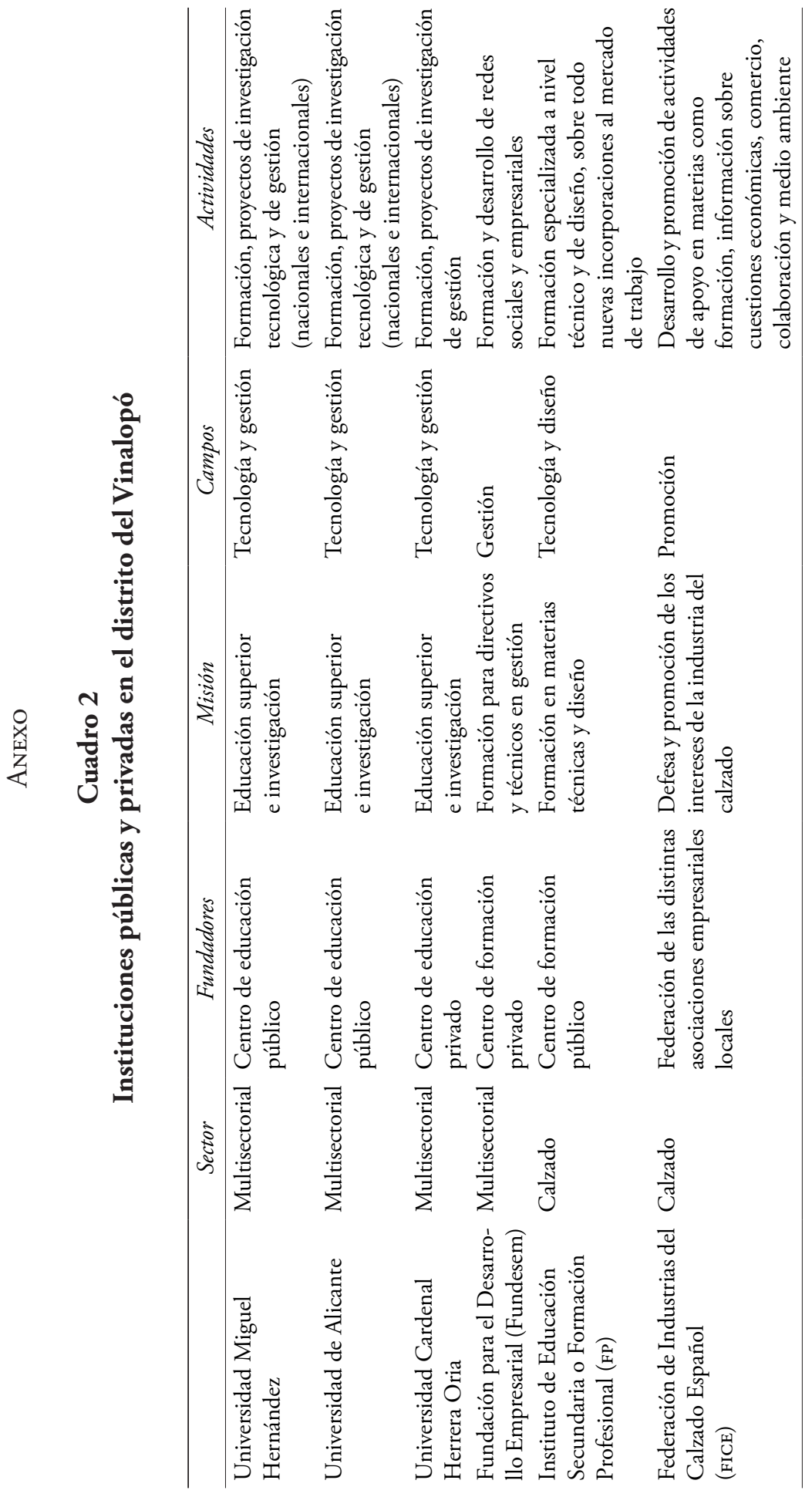




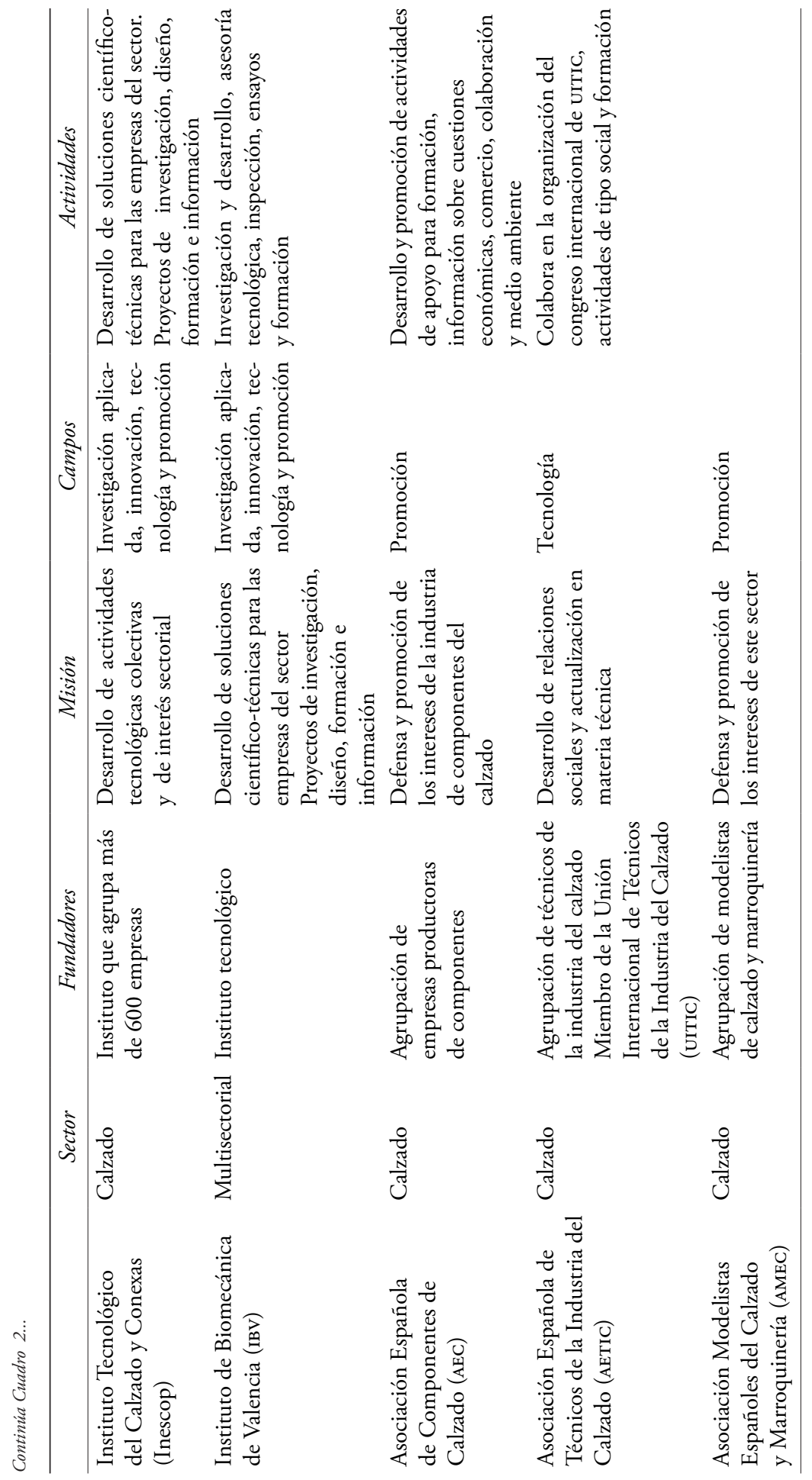




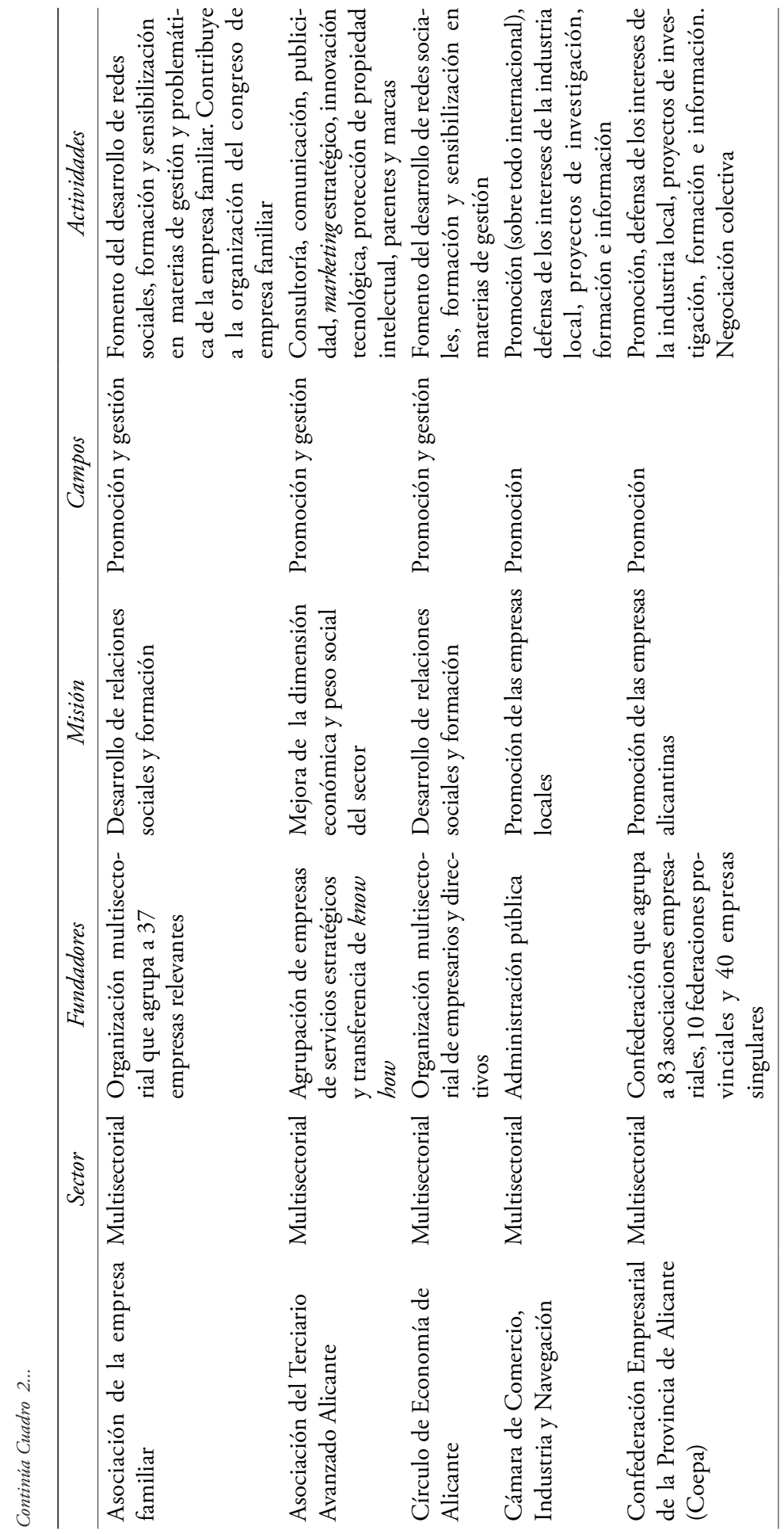




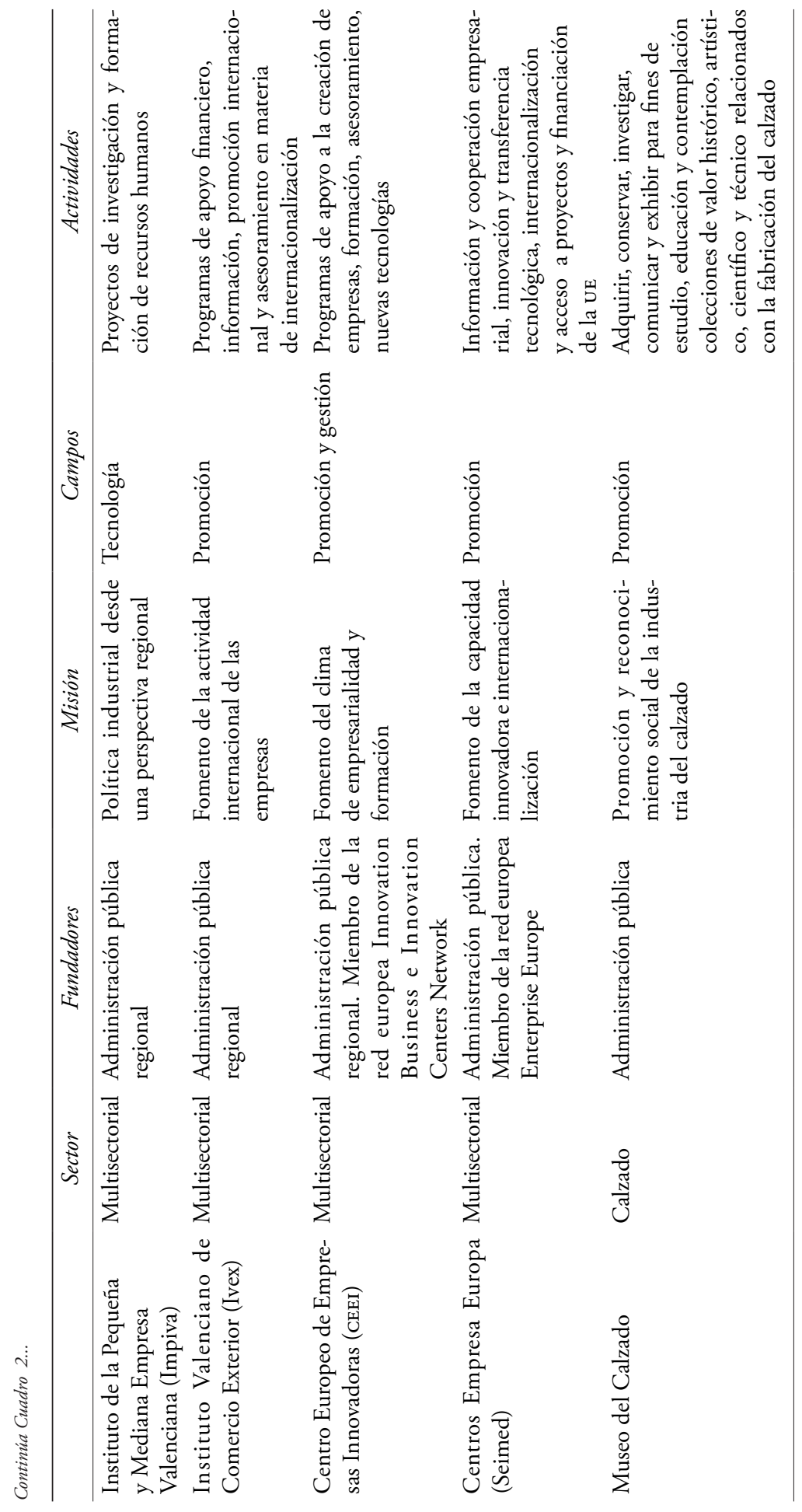




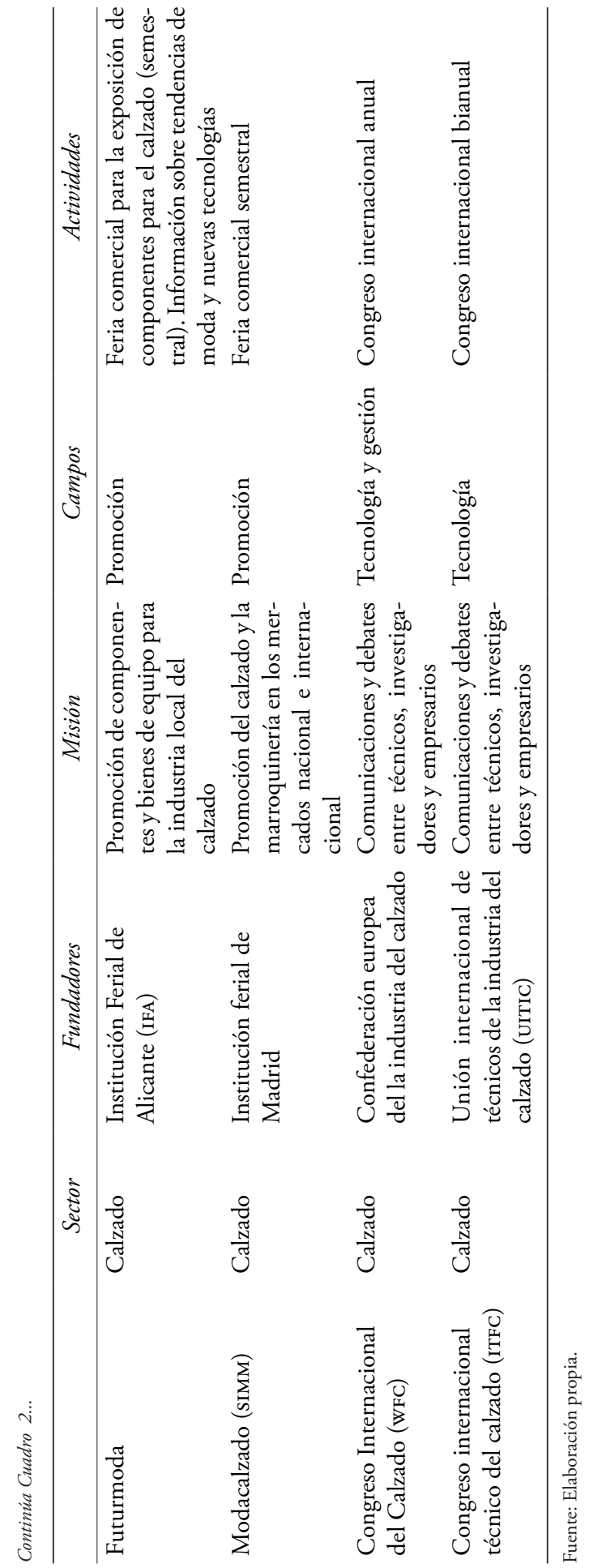




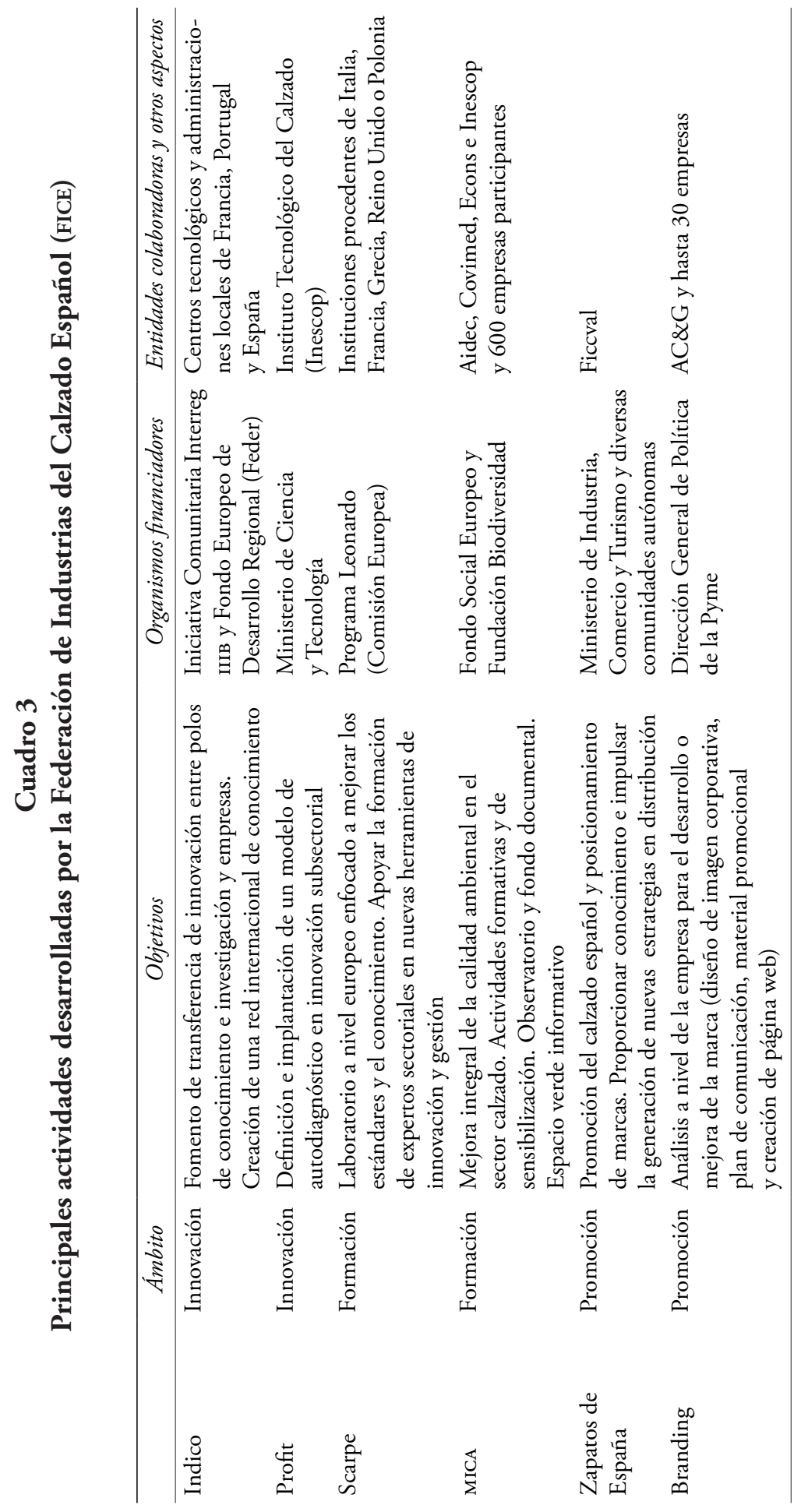




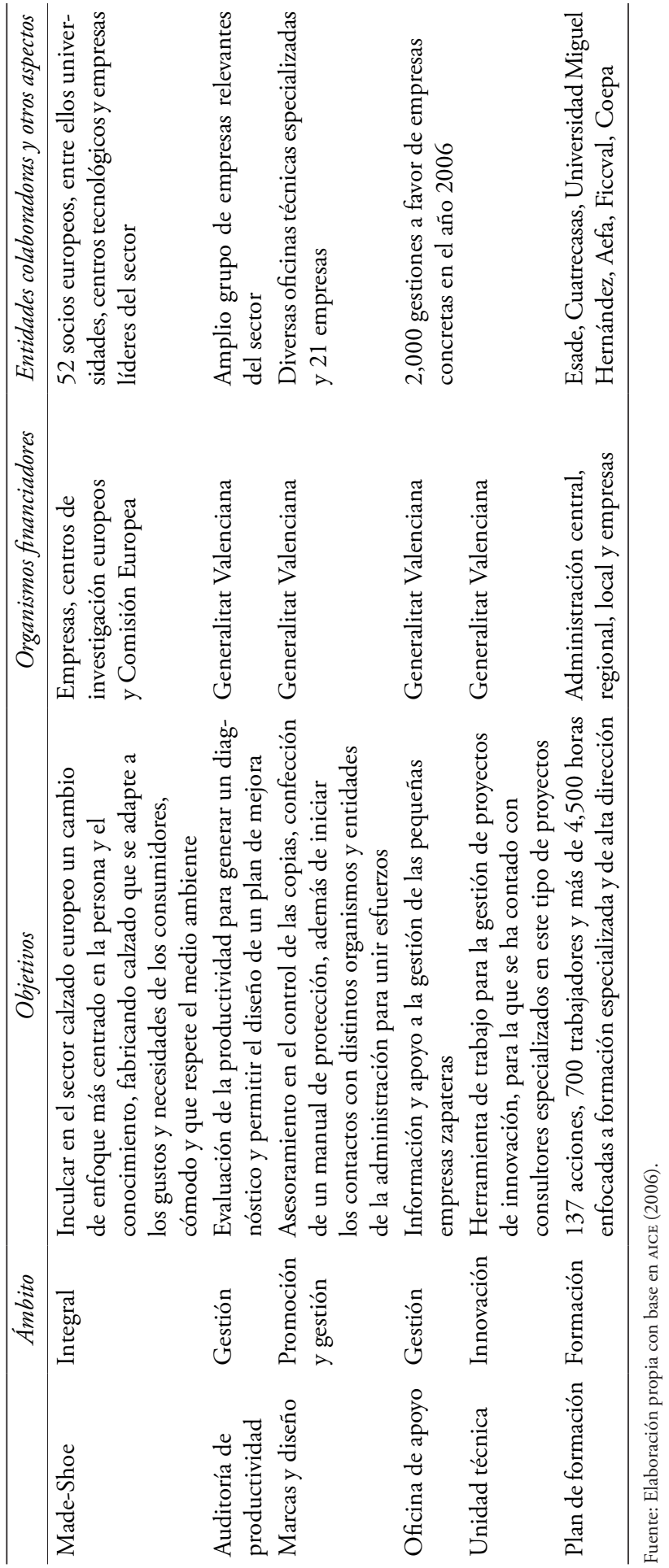




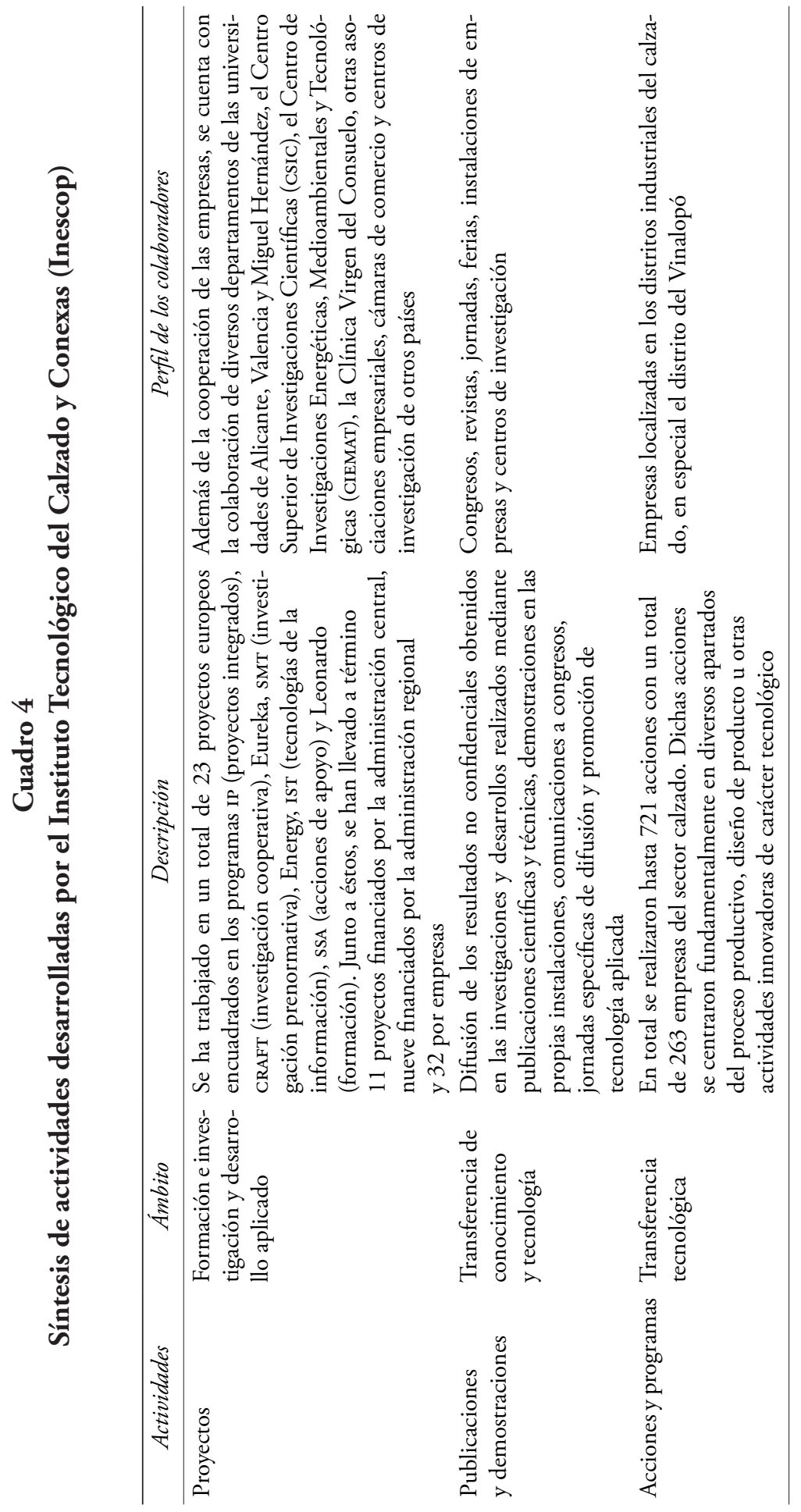




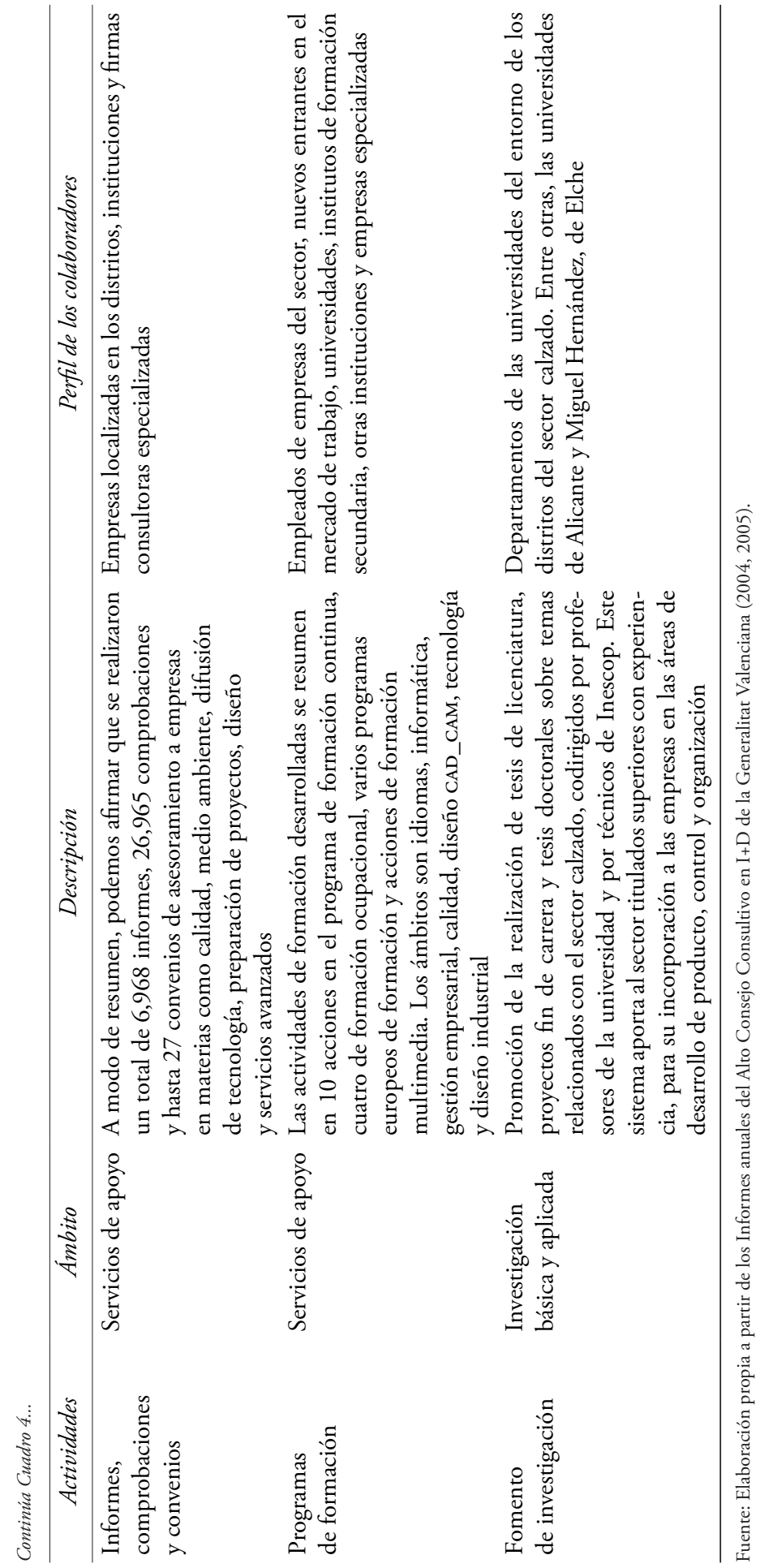




\section{Bibliografía}

AICE (Asociación de Industriales del Calzado de Elche) (2006), Memoria AICE, <http://economiaelche.com/file_download/99>, 20 de julio de 2007.

Albors-Garrigós, José y Francesc Xavier Molina-Morales (2001), “La difusión de la innovación, factor competitivo en redes interorganizativas. El caso de la cerámica valenciana", Economía Industrial, 339, Ministerio de Industria, Turismo y Comercio, Madrid, pp. 167-175.

Almeida, Paul y Bruce Kogut (1999), "Localization of knowledge and the mobility of engineers in regional networks", Management Science, 45 (7), Institut for Operations Research and the Management Sciences, Hanover, Maryland, pp. 905-916.

Alonso, José Luis y Ricardo Méndez (2000), Innovación, pequeñas empresa y desarrollo local en España, Cívitas, Madrid.

Alto Consejo Consultivo en I+D de la Generalitat Valenciana (2004), Informe anual, <http://www.pre.gva.es/altoconsejo/informesydictamenes2004>, 14 de junio de 2007.

Alto Consejo Consultivo en I+D de la Generalitat Valenciana (2005), Informe anual, <http://www.pre.gva.es/altoconsejo/informesydictamenes2005>, 16 de junio de 2007.

Aponte, Marinés (2002), Factores condicionantes de la creación de empresas en Puerto Rico: un enfoque institucional, Universidad Autónoma de Barcelona, Barcelona.

Basile, Roberto, Anna Giunta y Jeffrey Nugent (2003), "Foreign Expansion by Italian Manufacturing Firms in the Nineties: an Ordered Probit Analysis", Review of Industrial Organization, 23 (1), Springer, Nueva York, pp. 1-24.

Baum, Joel y Christine Olivier (1992), "Institutional embeddedness and dynamics of organizational populations", American Sociological Review, 57, American Sociological Association, Washington, pp. 540-559. 
Becattini, Giacomo (1989), "Los distritos industriales y el reciente desarrollo italiano", Sociología del Trabajo, 5, Siglo XXI, Madrid, pp. 3-17.

Becattini, Giacomo (1992), "El distrito industrial marshalliano como concepto socioeconómico", en Frank Pyke, Giacomo Becattini y Werner Sengenberger (eds.), Los distritos industriales y las pequeñas empresas I. Distritos industriales y cooperación interempresarial en Italia, Ministerio de Trabajo y Seguridad Social, Madrid, pp. 61-79.

Becattini, Giacomo, Marco Bellandi, Ottati Dei, Fabio Gabi y Sforzi (2001), Il caleidoscopio dello sviluppo locale, Rosenberg \& Sellier, Turín.

Becchetti, Leonardo y Stefania Rossi (2000), "The positive effect of industrial district on the export performance of Italian firms", Review of Industrial Organisation, 16 (1), Springer, Nueva York, pp. 53-68.

Belso-Martínez, José Antonio (2006), "Do industrial districts influence export performance and export intensity? Evidence for Spanish SME's internationalization process", European Planning Studies, 14 (6), Taylor \& Francis, Londres, pp. 791-810.

Belso-Martínez, José Antonio (2008), "Differences in survival strategies among footwear industrial districts: the role of international outsourcing", European Planning Studies, 16 (9), Taylor \& Francis, Londres, pp. 1229-1248.

Belussi, Fiorenza y Giorgio Gottardi (2000), Evolutionary patterns of local industrial systems: towards a cognitive approach to the industrial district, Ashgate, Aldershot.

Belussi, Fiorenza, Luciano Pilotti y Silvia Rita Sedita (2008), "Learning at the boundaries for industrial districts between exploitation of local resources and exploration of global knowledge flows", en Riccardo Leoncini y Sandro Montresor (eds.), Dynamic capabilities between firm organization and local systems of production, Routledge, Londres, pp. 181-215. 
Biggiero, Lucio (2002), "The location of multinationals in industrial districts: knowledge transfer in biomedicals", Journal of Technology Transfer, 27, Springer, Nueva York, pp. 111-122.

Boix, Rafael y Vittorio Galletto (2006), "El mapa de los distritos industriales de España”, Economía Industrial, 359, Ministerio de Industria, Turismo y Comercio, Madrid, pp. 165-184.

Boschma, Ron (2009), "Evolutionary economic geography and its implications for regional innovation policy", Papers in Evolutionary Economic Geography, 09-12, Universiteit Utrecht, Utrecht.

Boschma, Ron y Jan Lambooy (2002), "Knowledge, market structure, and economic coordination: Dynamics of industrial districts", Growth and Change, 33 (3), Wiley Periodicals, Massachusetts, pp. 291-311.

Brusco, Sebastiano (1992), "El concepto de distrito industrial: su génesis", en Frank Pyke, Giacomo Beccattini y Werner Sengenberger (eds.), Los distritos industriales y las pequeñas empresas I. Distritos industriales y cooperación interempresarial en Italia, Ministerio de Trabajo y Seguridad Social, Madrid, pp. 25-38.

Camagni, Roberto, Riccardo Fiorentini y Maurizio Mistri (2002), Scritti in onore di Benedetti Ennio, Cedam, Padua.

Camuffo, Arnaldo y Roberto Grandinetti (2005), "Distretti industriali in evoluzione, il ruolo dei knowledge business services", trabajo presentado en el encuentro L'internazionalizzazione delle imprese e dei distretti industriali, Urbino, 14 de abril.

Capo-Vicedo, Josep, Manuel Exposito-Langa y Enrique Masia-Buades (2007), "La importancia de los clusters para la competitividad de las Pyme en una economía global", EURE, 33 (98), Pontificia Universidad Católica de Chile, Santiago de Chile, pp. 119-133.

Caravaca, Inmaculada y Gema González (2009), "Las redes de colaboración como base del desarrollo territorial", Scripta. Nova Revista Electrónica de Geografía y Ciencias Sociales, 13 (289), Universidad de Barcelona, Barcelona, pp. 281-290. 
Caravaca, Inmaculada, Gema González y Rocío Silva (2005), "Innovación, redes, recursos patrimoniales y desarrollo territorial”, EURE, 23 (9), Pontificia Universidad Católica de Chile, Santiago de Chile, pp. 5-24.

Climent, Eugenio y RicardoMéndez (2002), "Medios innovadores y desarrollo local: los sistemas productivos de calzado del interior de España”, Estudios Geográficos, 63, Instituto Juan Sebastián el Cano-Csic, Madrid, pp. 5-31.

Cook, Gary y Robert Huggins (2002), "High technology clustering in Cambridge”, en Ash Amin, Stefano Goglio y Fabio Sforzi (eds.), The institutions of local development, IGU, Londres, pp. 2-28.

Cooke, Phillip, Patries Boekholt y Franz Tödtling (2000), The governance of innovation in Europe, Pinter, Londres.

Cooke, Philip (1999), "Regions in a global market: the experiences of Wales and Baden Wurttemberg", Review of International Political Economy, 4, Routledge, Londres, pp. 349-381.

Cooke, Philip (2002), Konwledge economies. Clusters, learning and cooperative adventage, Routledge, Londres.

Corò, Giovanni y Roberto Grandinetti (1999), "Evolutionary patterns of Italian industrial districts", Human Systems Management, 18 (2), Ios Press, Amsterdam, pp. 117-129.

Corò, Giovanni y Enzo Rullani (1998), Percorsi locali di internazionalizzazione, Franco Angeli, Milán.

Crestanello, Paolo y Pietro Dalla-Libera (2003), "International delocalisation of production: the case of the fashion industry of Vicenza", ponencia presentada en Clusters, industrial districts and firms: the challenge of globalization, Módena, Italia, 12-13 de septiembre.

DTI (Department of Trade and Industry) (2001), Business clusters in the $U K-A$ first assessment, DTI, Londres.

Enright, Michael (2001), "Regional clusters: what we know and what we should know", trabajo preparado para Kiel Institute Interna- 
tional Workshop on Innovation Clusters and Interregional Competition, Kiel, 12-13 de noviembre.

Garofoli, Gioacchino (ed.) (1992), Endogenous Development and Southern Europe, Aldershot, Avebury.

Garofoli, Gioacchino y Riccardo Mazzoni (1994), Sistemi produttivi locali: struttura e trasformazione, Franco Angeli, Milán.

Giner, José Miguel y María Jesús Santa María (2002), “Territorial systems of small firms in Spain: an analysis of productive and organizational characteristics in industrial districts", Entrepreneurship and Regional Development, 14 (3), Taylor \& Francis, Londres, pp. 211-228.

Giuliani, Elisa y Martin Bell (2005), "The micro-determinants of mesolevel learning and innovation: evidence from a Chilean wine cluster", Research Policy, 34, Elsevier, Amsterdam, pp. 47-68.

Gómez, Liyis, José María Veciana y David Urbano (2004), “Medidas de apoyo a la creación de empresas en el Caribe colombiano: análisis de la oferta y demanda de servicios", Investigación y Desarrollo, 12 (2), Universidad del Norte, Barranquilla, pp. 372-395.

Gottardi, Giorgio (1996), "Technology strategies, innovation without $\mathrm{R} \& \mathrm{D}$ and the creation of knowledge within industrial districts", Journal of Industry Studies, 3 (2), Routledge, Londres, pp. 119-134.

Guerrieri, Paolo, Simona Iammarino y Carlo Pietrobelli (2001), The global challenge to industrial districts: small and medium sized enterprises Italy and Taiwan, Edward Elgar, Cheltenham.

Hernández, Francesc y Vicent Soler (2003), "Cuantificación del 'efecto distrito' a través de medidas no radiales de eficiencia técnica", Investigaciones Regionales, 3, Asociación Española de Ciencia Regional, Barcelona, pp. 25-39.

Iammarino, Simona y Philip McCann (2006), "The Structure and Evolution of Industrial Clusters: Transactions, Technology and Knowledge Spillovers", Research Policy, 35 (7), Elsevier, Amsterdam, pp. 1018-1036. 
INE (Instituto Nacional de Estadística) (2007a), Directorio Central de Empresas, INE, Madrid.

INE (Instituto Nacional de Estadística) (2007b), Cuentas Económicas y de Comercio Exterior, INE, Madrid.

IPI (Istituto per la Promozione Industriale) (2002), L'esperienzia italiana dei distretti industriali, Ministero delle Attività Produttive, Roma.

Jessop, Bob (2001), "Institutional re(turns) and the strategic-relational approach", Environment and Planning A, 33, Pion, Londres, pp. 1213-1235.

Karlsson, Charlie y Johan Klaesson (2000), "Success in manufacturing employment in an industrial district: higher productivity or lower wages", Investigaciones Europeas de Dirección y Economía de la Empresa, 6 (2), Academia Europea de Dirección y Economía de la Empresa, Madrid, pp. 65-90.

Keeble, David y Frank Wilkinson (2000), High-technology clusters, networking and collective learning in Europe, Ashgate, Aldershot.

Landabaso, Mikel y Stuart Rosenfeld (2009), "Public policies for industrial districts and clusters", en Giacomo Becattini, Marco Bellandi y Lisa de Propris (eds.), A Handbook of Industrial Districts, Edward Elgar, Cheltenham, pp. 739-754.

Marshall, Alfred (1920), Principles of economics, MacMillan, Londres.

Martin, Ron y Peter Sunley (2003), "Deconstructing clusters: chaotic concept or policy panacea", Journal of Economic Geography, 3, Oxford University Press, Oxford, pp. 5-35.

Méndez, Ricardo (2006a), "La construcción de redes sociales y los procesos de innovación como estrategias de desarrollo rural", Problemas del Desarrollo, Revista Latinoamericana de Economía, 37 (147), Universidad Nacional Autónoma de México, México, pp. 217-240.

Méndez, Ricardo (2006b), "Del distrito industrial al desarrollo territorial: estrategias de innovación en ciudades intermedias", Desemvolvimento em Questâo, 7, Universidade Regional do Noroeste do Estado do Rio Grande do Sul, Ijuí, pp. 9-46. 
Méndez, Ricardo, Juan José Michelini y Patricia Romeiro (2006), "Redes socioinstitucionales e innovación para el desarrollo de las ciudades intermedias", Ciudad y Territorio, 148, Ministerio de Fomento, Madrid, pp. 377-395.

Miranda, José Antonio (1998), La industria del calzado en España (18601959): la formación de una industria moderna y los efectos del intervencionismo estatal, Instituto de Cultura Juan-Gil Albert, Alicante.

Miranda, José Antonio (2008), "Eficiencia colectiva y competitividad internacional: la exportación de los distritos industriales valencianos en el último tercio del siglo xx", trabajo presentado en el Ix Congreso Internacional de la Asociación Española de Historia Económica, Murcia, 9-12 de septiembre.

Mistri, Maurizio (1999), "Industrial districts and local governance in the Italian experience", Human System Management, 18, Ios Press, Amsterdam, pp. 131-139.

Molina-Morales, Francesc Xavier (2005), “The territorial agglomerations of firms: a social capital perspective from the Spanish title industry", Growth and Change, 36 (1), Wiley-Balckwell, New Jersey, pp. 74-99.

Molina-Morales, Francesc Xavier, Miguel Ángel López-Navarro y Jaume Guía-Julve (2002), "The role of local institutions as intermediary agents in the industrial districts", European Urban and Regional Studies, 9 (4), Sage, Londres, pp. 315-329.

Molina-Morales, Francesc Xavier y María Teresa Martínez-Fernández (2003), "The Impact of Industrial District Affiliation on Firm Value Creation", European Planning Studies, 11 (2), Taylor \& Francis, Londres, pp. 155-170.

Morrison, Andrea (2008), "Gatekeepers of Knowledge within Industrial Districts: Who They Are, How They Interact”, Regional Studies, 42 (6), Taylor \& Francis, Londres, pp. 817-835.

Paniccia, Ivana (1998), "One, a hundred, thousands industrial districts. Organizational variety of local networks of small and medium- 
sized enterprises", Organization Studies, 4, Sage, Londres, pp. 667-699.

Paniccia, Ivana (1999), "The performance of IDs. Some insights from the Italian case", Human Systems Management, 18, Ios Press, Amsterdam, pp. 141-159.

Parolini, Cinzia y Federico Visconti (2003), "Footwear manufacturing districts: the effects of internazionalisation, delocalisation and new technologies", trabajo presentado en la conferencia Clusters, industrial districts and firms: the challenge of globalization, Módena, Italia, 12-13 de septiembre.

Parrilli, Mario Davide (2004), "A stage and eclectic approach to industrial district development: two policy keys for survival clusters in developing countries", European Planning Studies, 12 (8), Taylor \& Francis, Londres, pp. 1115-1131.

Pilotti, Luciano (2000), "Networking, strategic positioning and creative knowledge in industrial districts", Human Systems Management, 19, Ios Press, Amsterdam, pp. 121-133.

Pla-Barber, José y Francisco Puig (2009), "Is the influence of the industrial district on international activities being eroded by globalization?: Evidence from a traditional manufacturing industry", International Business Review, 18 (5), Elsevier, Amsterdam, pp. 435-445.

Pyke, Frank y Werner Segenberger (eds.) (1992), Industrial Districts and Local Economic Regeneration, International Institute for Labour Studies, Génova.

Rullani, Enzo (1998), "Reforma delle istitzioni e sviluppo locale", Sviluppo Locale, 5 (8), Rosenberg \& Sellier, Turín, pp. 5-46.

Salom, Julia (2003), "Innovación y actores locales en los nuevos espacios económicos: un estado de la cuestión", Boletín de la Asociación de Geógrafos Españoles, 36, Asociación de Geógrafos Españoles, Madrid, pp. 7-30.

Salom, Carrasco Julia y Juan M. Albertos Puebla (2006), "Redes institucionales y servicios a las empresas en el cluster cerámico de Cas- 
tellón", Scripta. Nova Revista Electrónica de Geografía y Ciencias Sociales, 213, Universidad de Barcelona, Barcelona, <http://www. ub.edu/geocrit/sn/sn-213.htm>, 5 de marzo de 2007.

Salom, Julia y Juan Albertos (2009), Redes socioinstitucionales, estrategias de innovación como base del desarrollo territorial en España, Universidad de Valencia, Valencia.

Sforzi, Fabio (1992), "Importancia cuantitativa de los distritos industriales marshallianos en la economía italiana”, en Frank Pyke, Giacomo Becattini y Werner Sengenberger (eds.), Los distritos industriales y las pequeñas empresas I. Distritos industriales y cooperación interempresarial en Italia, Ministerio de Trabajo y Seguridad Social, Madrid, pp. 11-145.

Soler, Vicent (2001), "Verificación de las hipótesis del efecto distrito", Economía Industrial, 334, Ministerio de Industria, Turismo y Comercio, Madrid, pp. 13-23.

Spaventa, Alessandro y Salvatore Monni (2005), "Productive internationalisation: analysis of the potential effects on Veneto's traditional industrial districts", Monitoring Italy 2005: productivity, growth and competitiveness, conferencia organizada por el Institute for Estudies and Economic Analysis, Roma, 7 de mayo.

Spaventa, Alessandro y Salvatore Monni (2007), "What's next? How the internalization process might lead to the dissolution of Veneto's low-technology industrial districts?”, Working Paper 3/2007, CREI, Università degli Studi, Roma.

Tomás, Juan Antonio y Juan Such (1997), "Internationalisation of small and medium firms in four Valencia region industrial districts", Quaderns de Politica Económica, 7, Universitat de València, Valencia, pp. 1-18.

Tomás, Juan Antonio, Miguel Torrejón y Juan Such (1997), "Producción flexible, redes empresariales y sistemas territoriales de pequeña y mediana empresa", Sociología del Trabajo, 30, Siglo XXI, Madrid, pp. 21-42.

Tomás, Juan Antonio, José Luis Contreras y Salvador del Saz (2000), "Institutos tecnológicos y política sectorial en distritos industria- 
les. El caso del calzado", Economía Industrial, 334, Ministerio de Industria, Turismo y Comercio, Madrid, pp. 25-34.

Tortajada, Enrique, Ignacio Fernández y Josep Antoni Ybarra (2005), "Evolución de la industria española del calzado: factores relevantes en las últimas décadas", Economía Industrial, 355, Ministerio de Industria, Turismo y Comercio, Madrid, pp. 211-227.

Triglia, Carlo (1993), "Distritos industriales italianos: ni mito ni interludio", en Frank Pyke y Werner Sengenberger (eds.), Los distritos industriales y las pequeñas empresas III. Distritos industriales y regeneración económica local, Ministerio de Trabajo y Seguridad Social, Madrid, pp. 63-80.

Urbano, David (2003), Factores condicionantes de la creación de empresas en Cataluña: un enfoque institucional, Universidad Autónoma de Barcelona, Barcelona.

Vaccà, Sergio (1994), "Le imprese transnazionali tra sistemi locali e sisteme globali", Economia e Política Industriale, 84, Franco Angeli, Milán, pp. 8-21.

Vázquez-Barquero, Antonio (1993), Política económica local. La respuesta de las ciudades a los desafios del ajuste productivo, Pirámide, Madrid.

Ybarra, Josep Antoni (1991), "Determinación cuantitativa de distritos industriales: la experiencia del País Valenciano", Estudios Territoriales, 37, Ministerio de Obras Públicas, Transportes y Comunicaciones-Instituto del Territorio y Urbanismo, Madrid, pp. 53-67.

Ybarra, Josep Antoni y María Jesús Santa María (2005), "El sector del calzado en España: retos ante un contexto de globalización", Boletín Económico de ICE, 2838, Ministerio de Industria, Turismo y Comercio, Madrid, pp. 9-23.

Ybarra, Josep Antoni y María Jesús Santa María (2006), “El sector del juguete en España: dinámica y estrategias productivas ante el proceso de globalización", Boletín Económico de ICE, 2885, Ministerio de Industria, Turismo y Comercio, Madrid, pp. 21-33.

Zucchella, Antonella (2006), "Local cluster dynamics: trajectories of mature industrial districts between decline and multiple embedded- 
ness", Journal of Institutional Economics, 2 (1), Cambridge University Press, Cambridge, pp. 21-44.

Recibido: 16 de junio de 2009. Reenviado: 23 de julio de 2010. Aceptado: 1 de febrero de 2011.

José Antonio Belso-Martínez. Ha desempeñado su labor a lo largo de los últimos quince años en los departamentos de Economía Aplicada y Política Económica (Universidad de Alicante), Economía y Empresa (Universidad Cardenal Herrera-CEU) y Estudios Económicos y Financieros (Universidad Miguel Hernández). Sus trabajos sobre internacionalización, entrepreneurship o políticas públicas han sido publicados en prestigiosas revistas científicas indexadas en JCR, Econ-Lit o Latindex; entre dichas revistas se encuentran: Enviroment and Planning C, European Planning Studies, Entrepreneurship and Regional Development, Estudios de Economía, Estudios de Economia Aplicada, Revista Asturiana de Economía o Cuadernos Aragoneses de Economía. En ocasiones, estos trabajos han sido transferencia de investigaciones financiadas mediante fondos públicos o privados. En concreto cabe destacar los proyectos realizados gracias a los fondos proporcionados por el Instituto de la Pequeña y Mediana Empresa Valenciana (Generalitat Valenciana), la Unión Europea o la Consellería de Empresa, Universidad y Ciencia. Áreas de Investigación: entrepreneurship, internacionalización y deslocalización de actividades económicas, distritos industriales y clusters.

María José López-Sánchez. Ha desempeñado su labor a lo largo de los cinco últimos años en los departamentos de Economía Aplicada y Política Económica (Universidad de Alicante) y Estudios Económicos y Financieros (Universidad Miguel Hernández, de Elche). Antes ocupó diversas responsabilidades en la Confederación Empresarial de la Provincia de Alicante (Coepa). Sus principales publicaciones y comunicaciones a congresos se centran esencialmente en el rol de las instituciones locales en los clusters y las políticas de envejecimiento activo. Ha participado como investigadora en más de cinco proyectos internacionales cofinanciados por la Unión Europea. Áreas de investigación: envejecimiento activo, distritos industriales y clusters. 